\title{
Causas de custos adicionais e impacto financeiro em obras públicas sob a perspectiva da gestão de risco
}

\author{
Causes of cost overrun and financial impact on public \\ works from risk management perspective
}

\section{Maria Carolina Gomes de Oliveira Brandstetter Helen Regina de Oliveira e Ribeiro}

\section{Resumo}

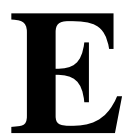

ste trabalho tem por objetivo analisar as principais causas da contratação de serviços adicionais com impacto financeiro na construção de obras públicas, sob a perspectiva da gestão de risco. Uma revisão sistemática da literatura propiciou uma nova categorização das causas dos custos adicionais com base na taxonomia do risco. A etapa de campo envolveu a análise de contratos de obras novas e concluídas de uma autarquia federal vinculada ao ensino superior. Para análise das causas, foi realizada uma análise lexical das justificativas dos aditivos, por meio do software Iramuteq. A categorização das causas resultantes da revisão da literatura embasou a definição de cada categoria de risco. O impacto financeiro para cada categoria de risco foi mensurado por análises quantitativas. Os resultados apontam que o maior índice de risco corresponde à categoria de projetos, com $53 \%$ da frequência dos aditivos e $56 \%$ do impacto financeiro. As contribuições da pesquisa envolvem o modelo proposto para análise das causas dos custos adicionais baseado na taxonomia do risco e a associação das análises lexical e documental para redução da subjetividade e melhoria na condução do processo de mitigação do risco.

Palavras-chave: Custos adicionais. Gestão de riscos. Obras públicas.

\begin{abstract}
This paper aims to analyse the main causes for contracting additional services in public construction works, from a risk management perspective. A systematic literature review led to a new categorisation of the causes of cost overrun based on risk taxonomy. The field study involved an analysis of contracts for new and completed works at a public higher education institution. The Iramuteq software performed a lexical analysis of the justifications for the additions. The categorisation of the causes resulting from the literature review supported the definition of each risk category. The financial impact for each risk category was measured by quantitative analysis. The results indicate that the highest risk index corresponds to the project category, with 53\% of addition frequency and 56\% of financial impact. The contributions of this study involve the proposed model for analysis of the causes of cost overrun based on risk taxonomy and the association of lexical and documentary analyses to reduce subjectivity and improve the risk mitigation process.

Keywords: Cost overrun. Risk management. Public works.
\end{abstract}

${ }^{1}$ Maria Carolina Gomes de Oliveira Brandstetter ${ }^{1}$ Universidade Federal de Goiás Goiânia - GO - Brasil

${ }^{2}$ Helen Regina de Oliveira e Ribeiro 2 Universidade Federal de Goiás Goiânia - GO - Brasil

Recebido em 25/03/19 Aceito em 10/09/19 


\section{Introdução}

Nas últimas décadas a compreensão dos fatores determinantes dos custos adicionais em empreendimentos, envolvendo obras públicas e privadas, tornou-se objeto de estudo de várias pesquisas em âmbito mundial. Oladapo (2007) estudou as fontes predominantes de variação do custo e do prazo de obras na Nigéria; Enshassi, Al-Najjar e Kumaraswamy (2009) compararam as percepções de empreiteiros, consultores e proprietários em Gaza; Love et al. (2010) estudaram os custos adicionais de projetos de infraestrutura na Austrália; Fidan et al. (2011) apresentaram uma ontologia para relacionar conceitos referentes a riscos na Turquia; Ahiaga-Dagbui e Smith (2013) desenvolveram modelos de mineração dos dados em projetos de infraestrutura no Reino Unido; Cheng (2014) propõe uma variação do método Delphi para adicionais de custo em Taiwan; Shehu, Endut e Akintoye (2014) destacaram os problemas financeiros dos subempreiteiros em obras na Malásia; Santos, Starling e Andery (2015) apontaram as falhas no processo de projeto em obras no Brasil; Muianga, Granja e Ruiz (2015) desenvolveram estrutura de categorização para adicionais de prazos e custos; e Beltrão e Carvalho (2019) apresentaram um modelo para identificar e priorizar riscos em obras públicas brasileiras.

Esses fatores estão relacionados aos diversos agentes da indústria da construção, como construtoras, subempreiteiros, fornecedores, projetistas, agentes financeiros, consultores, clientes, empresas e autoridades governamentais. Continuamente as causas para tais contratações adicionais envolvem ineficiência na gestão dos contratos, mudanças de escopo do projeto, ausência de controle de custos, entre outros fatores associados aos desvios do que foi planejado.

Na perspectiva da gestão de risco, a diferença entre os resultados almejados e reais de um projeto é atribuída a um evento de risco, definido como o efeito da incerteza nos objetivos, tais como a meta financeira (ABNT, 2018). Tal incerteza envolve causas, consequências, probabilidade de ocorrências, fatores de vulnerabilidade, os quais nem sempre são considerados de forma diferenciada nos estudos que envolvem a análise de fatores de risco.

Este trabalho parte do pressuposto que a análise de causas de custos adicionais deve considerar de forma diferenciada os diversos conceitos que abrangem a gestão de risco, de modo a propiciar o desenvolvimento de estratégias mais eficazes de mitigação. Um dos propósitos da pesquisa é propor uma categorização para análise do risco, cujas informações conduzam para os fatores de vulnerabilidade que afetam o impacto dos riscos em um projeto.

No caso das obras públicas, objeto de estudo da presente pesquisa, as contratações são processos que promovem considerável responsabilidade a todos os designados para cada uma das etapas desses processos, tanto por envolver recursos públicos como pela importância dessas obras para as comunidades beneficiadas.

A existência de serviços adicionais em obras públicas, entretanto, não pode ser sinônimo de malversação de dinheiro público. Sua contratação é legítima e prevista em lei. Todavia, os gestores públicos precisam estar atentos para evitar que essas contratações signifiquem ganhos indevidos das empresas e consequente prejuízo aos cofres públicos (MENEZES, 2013).

Diante desse contexto, o objetivo do presente estudo é realizar uma análise das causas que levam à contratação de serviços adicionais em contratos de construção de obras públicas e analisar o impacto financeiro dessas contratações sob a perspectiva da gestão de risco.

A compreensão das causas dos custos adicionais em obras públicas ocorreu por meio da análise da literatura pertinente e de um estudo de campo realizado em uma autarquia federal relacionada ao ensino superior localizada no estado de Goiás.

A pesquisa também busca contribuir propondo uma categorização para análise das causas dos custos adicionais considerando a taxonomia baseada na literatura internacional, que possa auxiliar outras pesquisas na rastreabilidade da causa-raiz, organizando os diversos conceitos geralmente tratados de forma indistinta.

Outra contribuição do trabalho encontra-se no desenvolvimento de uma mensuração do risco relativo ao custo adicional de forma diferenciada de outros trabalhos que utilizam a percepção de entrevistados, podendo atribuir subjetividade à avaliação. É proposta a mensuração por meio de análise documental em conjunto com análises lexicais cujos cálculos estatísticos por análises multivariadas conferem maior robustez para a análise dos dados textuais. Parte-se do pressuposto de que a construção dos índices de risco associados a cada categoria de causa se beneficie da precisão de dados registrados. 


\section{Referencial teórico}

Sob a ótica da gestão de risco, a diferença entre os resultados esperados e reais de um projeto é atribuída a eventos de risco, gerenciados em todas as etapas de execução do projeto. O risco é definido como a consequência da incerteza nos objetivos, podendo ser visto como um desvio em relação ao esperado, positivo e/ou negativo. Normalmente o risco é expresso em termos de fontes de risco, eventos, consequências e probabilidades, segundo a ISO 31000 (ABNT, 2018) e ISO/TR 31004 (ABNT, 2015).

A Figura 1 ilustra o processo de avaliação de riscos baseado na ISO 31000 (ABNT, 2018) e ISO/IEC 31010 (ABNT, 2012).

O processo de avaliação de risco engloba a identificação, seguida da análise e avaliação de riscos.

\section{Identificação do risco}

A identificação do risco parte do reconhecimento da organização em relação aos eventos que possam distanciála do alcance dos seus objetivos.

No contexto do presente trabalho, a identificação do risco está relacionada aos custos adicionais de obras públicas.

Comumente no âmbito da construção são propostas listas de verificação genéricas para facilitar a identificação dos fatores de risco, agrupados em diferentes categorias.

Geralmente fontes, eventos e consequências do risco são definidos na mesma lista, podendo dificultar uma análise que conduza à mitigação do risco (TAH; CARR, 2000; DIKMEN; BIRGONUL; FIDAN, 2008). Um evento de risco acontece porque a incerteza presente em um projeto é acompanhada de pelo menos uma causa, uma consequência e a probabilidade de ocorrência (CANO; CRUZ, 2002; FIDAN et al., 2011).

Partindo da premissa de que os custos adicionais dependem de relações causais entre várias fontes de risco e vulnerabilidade, Fidan et al. (2011) desenvolveram uma ontologia para relacionar tais conceitos, buscando suprir a lacuna da criação de um vocabulário comum. Os autores propuseram uma taxonomia da inter-relação dos termos associados ao risco. O termo taxonomia é entendido como sistema de classificação multidimensional (PUGH; HICKSON; HININGS, 1969). A Figura 2 ilustra um esquema representativo de exemplos da taxonomia do risco proposta por Fidan et al. (2011).

Alguns fatores de vulnerabilidade podem afetar a probabilidade de ocorrência de risco, por exemplo, a instabilidade econômica e a falta de clareza em relação aos objetivos do cliente. Se o fator tem potencial de causar um evento de risco, é identificado como fonte de risco. Se for o resultado do evento de risco, é uma consequência de risco. O adicional de custo é entendido como uma consequência de risco, resultado, por exemplo, do evento de risco atraso que, por sua vez, pode derivar dos fatores que são fonte de risco como alterações adversas, como uma mudança de escopo e aspectos relacionados ao projeto.

Figura 1 - Processo de avaliação de riscos e atividades correspondentes por etapas

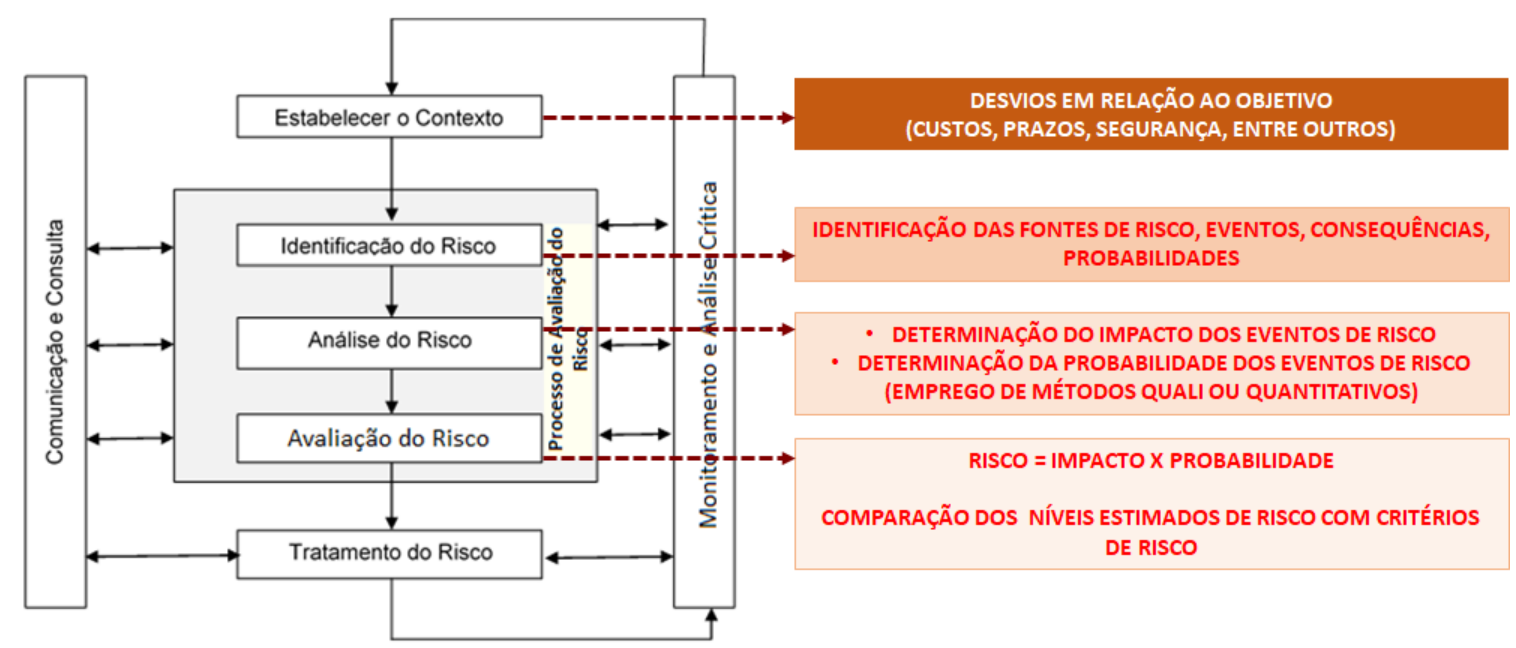


Figura 2 - Inter-relação dos termos relacionados ao risco

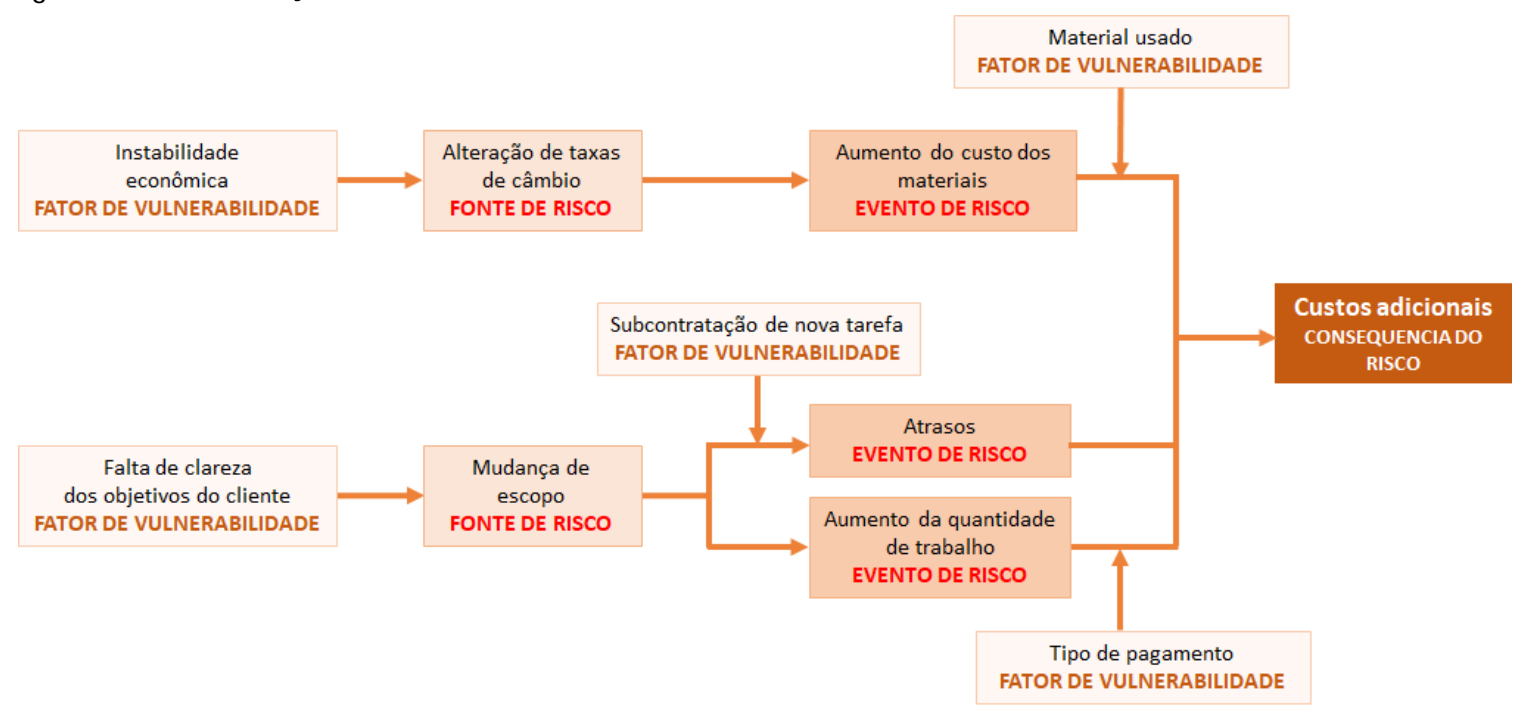

Fonte: adaptado de Fidan et al. (2011).

\section{Análise e avaliação dos riscos}

Na análise e avaliação de riscos, convém que o processo seja conduzido de forma sistemática.

A análise de riscos compreende a consideração das fontes e dos eventos de risco, buscando entender impactos e probabilidades de ocorrência.

Conforme preconiza a norma ISO/IEC 31010 (ABNT, 2012), vários métodos podem ser utilizados para identificação dos impactos e probabilidades das fontes e eventos de risco. Tais métodos podem ser quantitativos, qualitativos ou semiquantitativos, cuja escolha também depende da disponibilidade de dados confiáveis.

Tanto a análise do impacto quanto da probabilidade pode variar desde descrições simples de resultados até modelagens quantitativas.

A análise de impacto determina a natureza e o tipo de impacto que pode ocorrer para cada evento particular que ocorreu. Sua descrição pode envolver a consideração de controles existentes para estimativas mais precisas.

Quanto às análises e estimativas de probabilidades, a norma ISO/IEC 31010 (ABNT, 2012) preconiza a utilização de dados históricos, quando disponíveis, as previsões de probabilidade utilizando técnicas preditivas ou ainda a opinião de especialistas. Contudo, cabe destacar que os julgamentos desses agentes recorrem a todas as informações pertinentes, incluindo informações históricas.

No âmbito da construção, especificamente no contexto da gestão de risco, ao avaliar as causas para a ocorrência de custos adicionais, comumente os autores mensuram a importância e/ou frequência das causas baseados na percepção, por meio de entrevistas, de grupos de intervenientes como supervisores de obras, projetistas, profissionais do órgão público, entre outros (CHENG, 2014; ENSHASSI; AL-NAJJAR; KUMARASWAMY, 2009; SANTOS; STARLING; ANDERY, 2015).

Nesses trabalhos o risco associado ao adicional do custo previamente planejado é calculado pela combinação de índices de importância e frequência das causas, provenientes das percepções dos entrevistados que são convidados a informar sua noção de impacto e frequência de cada causa. Nesse tipo de avaliação pode ocorrer um tipo de comportamento ressaltado por autores como Santos, Starling e Andery (2015) de que a percepção de um grupo de entrevistados pode diferir de outro grupo, podendo haver uma tendência de ressaltar problemas respectivos às outras esferas de atuação. Esse possível mecanismo de defesa dos agentes em relação a suas responsabilidades também foi ressaltado em outros trabalhos (MCGRAW..., 2014; SHELBOURN et al., 2007), indicando ser mais fácil evidenciar problemas fora de sua área de atuação, indicando uma ausência de visão sistêmica e responsabilidade conjunta por todos os possíveis fatores de risco. Esse tipo de comportamento pode levar a distorções ao avaliar probabilidades e importância das causas de eventos de risco como os adicionais de prazo e custo. 
Poucos trabalhos que avaliaram causas de custos adicionais não utilizaram por método a entrevista com envolvidos nos processos de orçamentação, licitação, projeto e construção. Um dos únicos exemplos é o trabalho de Menezes (2013), que estudou as causas dos aditivos contratuais em obras públicas de uma instituição federal do ensino superior baseando-se em pesquisa documental a partir da análise das causas registradas para cada aditivo contratual. Tais causas foram analisadas com base nas justificativas registradas pelos responsáveis contratados e classificadas segundo duas vertentes: falhas de procedimentos na elaboração dos projetos básicos e alterações que decorrem de necessidades surgidas após a contratação da obra; contudo não houve o objetivo da mensuração voltada ao risco dos custos adicionais.

Na etapa de avaliação do risco, o impacto e a probabilidade serão combinados para determinar um nível de risco. Quanto maior a precisão na definição do impacto e da probabilidade para cada fator ou evento de risco, mais assertiva a avaliação será, permitindo melhor tomada de decisão acerca de ações futuras sobre tratamento dos riscos.

A avaliação permite determinar a significância do nível e do tipo de risco, podendo-se fazer uso de diferentes técnicas e métodos, como análise de causa-raiz, definição de índices de risco e construção de matriz probabilidade e impacto (ABNT, 2012).

A natureza e o grau de incerteza requerem o entendimento da qualidade, quantidade e integridade das informações disponíveis sobre o risco, suas fontes, causas e consequências para o atendimento do objetivo definido no contexto da gestão de risco (ABNT, 2012).

\section{Método de pesquisa}

A pesquisa, segundo seus objetivos, pode ser classificada como descritiva (GIL, 2008), pois tem como finalidade a descrição de fatos e fenômenos de determinada realidade, estabelecendo relações entre as variáveis (TRIVIÑOS, 1987).

A pesquisa abrangeu uma etapa inicial que envolveu uma extensa revisão da literatura com o propósito de gerar uma categorização para análise das causas dos custos adicionais baseada na taxonomia da gestão de riscos. Nessa etapa foi desenvolvida uma revisão sistemática da literatura.

Posteriormente, a etapa de campo procurou investigar dados relativos à contratação de serviços adicionais em obras públicas. Para essa etapa, buscou-se uma autarquia que apoiasse a pesquisa para a realização de um estudo de caso. O levantamento dos dados ocorreu em uma instituição pública federal de ensino superior do estado de Goiás.

A pesquisa foi conduzida considerando as etapas descritas no fluxograma da Figura 3.

\section{Construção da categorização de causas de custos adicionais por meio de RSL}

Com o intuito de propor uma nova categorização para o risco relacionado ao adicional de custo em empreendimentos, foi conduzida uma revisão sistemática da literatura (RSL), baseada nos métodos propostos por Kitchenham (2004), Muianga, Granja e Ruiz (2015) e Dresch, Lacerda e Antunes Júnior (2015).

O levantamento buscou revisar as pesquisas que categorizaram as causas responsáveis pelos custos adicionais no âmbito da construção. Buscou-se verificar se as causas levantadas poderiam ser categorizadas em uma compilação das classificações anteriores, cujos estudos em sua grande maioria são baseados em levantamentos de opinião dos diversos agentes envolvidos com os empreendimentos.

As bases selecionadas como saída de dados neste trabalho foram: Scopus, Sience Direct, Wiley e Web of Knowledge. O cruzamento de strings de busca relacionou como entradas principais: "cost overrun” e "construction".

A Tabela 1 ilustra o processo de filtragem utilizado na RSL.

Dos 1.753 trabalhos iniciais encontrados, foram realizados filtros para excluir artigos que não abordavam o tema no âmbito da construção, restando 575 trabalhos. Uma amostragem por bola de neve foi conduzida e um novo filtro foi realizado pela leitura de abstracts, privilegiando os estudos que tiveram similaridade quanto ao objeto de estudo, obras públicas. Essa filtragem reduziu o escopo para 89 trabalhos a serem lidos na íntegra. O filtro final levou a um total de 36 trabalhos aderentes ao tema.

O resultado da RSL levou a uma proposta de categorização baseada na taxonomia do risco que considera de forma distinta os termos: fontes de vulnerabilidade, fonte e evento de risco. 
Figura 3 - Fluxograma das etapas da pesquisa

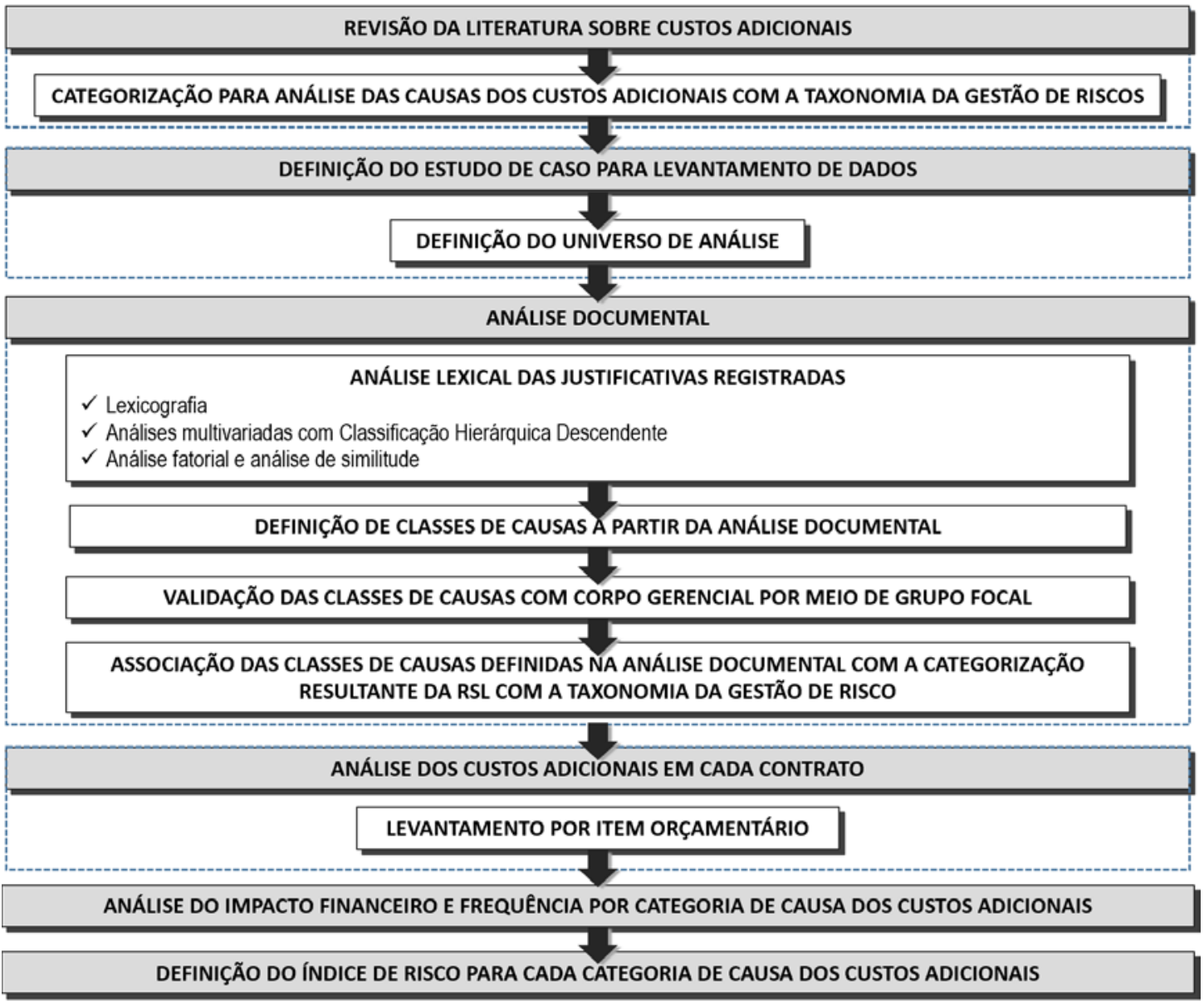

Tabela 1 - Processo de filtragem conduzido na RSL

\begin{tabular}{|c|c|c|}
\hline \multicolumn{2}{|c|}{ Base de dados (Scopus, Sience Direct, Wiley e Web of Knowledge) } & $\begin{array}{c}\text { Trabalhos } \\
\text { encontrados }\end{array}$ \\
\hline Palavras-chave & "cost overrun" e "construction" & 1753 \\
\hline \multirow{5}{*}{ 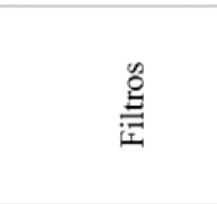 } & $1^{0}$ Leitura dos temas - menos 1178 & 575 \\
\hline & $2^{0}$ Sem duplicidades - menos 56 & 519 \\
\hline & $3^{0}$ Leitura dos resumos - menos 446 & 73 \\
\hline & $4^{0}$ Amostragem Bola de Neve $(\mathrm{ABN})-$ mais 16 & 89 \\
\hline & $5^{0}$ Leitura na íntegra - menos 53 & 36 \\
\hline
\end{tabular}

\section{Estudo de caso e definição do universo de análise}

O método do estudo de caso seguiu os procedimentos definidos por Yin (2015), que podem ser resumidos nas etapas:

(a) revisão bibliográfica para estruturação conceitual e metodológica;

(b) definição dos critérios para seleção do caso e seleção da instituição - foi escolhida uma autarquia que atendeu aos critérios da existência de banco de dados de obras já concluídas, incluindo os registros relativos às contratações adicionais, além da disponibilidade e do interesse nos propósitos da pesquisa. $\mathrm{O}$ levantamento dos dados ocorreu em uma instituição pública federal de ensino superior do estado de Goiás;

(c) condução de um estudo inicial para construção do protocolo do estudo de caso - esta etapa incluiu a ambientação com órgão responsável pelos contratos de todas as obras da instituição. O estudo inicial permitiu o acesso ao banco de dados para reconhecimento das informações disponíveis dos procedimentos licitatórios. O entendimento da qualidade da informação presente nos registros dos contratos das obras foi 
fundamental para definição das análises de cada adicional de custo nos contratos. De forma sintética, esta etapa conduziu à forma de coleta dos dados para quantificação do impacto financeiro e frequência dos custos adicionais que compõem o nível de risco;

(d) condução da coleta dos dados, explicitada a seguir; e

(e) análise conjunta de várias fontes de dados e evidências, incluindo planilhas e documentos de análise financeira dos contratos, fluxogramas dos processos relativos à licitação e fiscalização das obras, relatórios de fiscalização para análise dos registros de justificativas dos adicionais e entrevistas com o corpo gerencial da autarquia.

Posteriormente iniciou-se o levantamento dos dados na autarquia federal selecionada. Foi feita a definição do universo de análise, abrangendo os contratos de construção e ampliação de novos edifícios, decorrentes de processos de licitação dos tipos tomada de preços ou concorrência, concluídas entre os anos de 2010 e 2014.

Esse recorte foi intencional, pois engloba um período em que a autarquia ampliou o número de obras em decorrência da criação do Programa de Apoio à Reestruturação e Expansão das Universidades Federais (REUNI) iniciado em 2008, resultando na duplicação de sua área construída. O recorte permitiu a análise das principais obras finalizadas no período, que guardam similaridade entre si, em termos de área construída, tipologia construtiva e destinação ao ensino.

A coleta dos dados partiu de uma leitura minuciosa de todos os contratos selecionados, com destaque para os documentos que fazem referências às contratações de serviços adicionais como os relatórios de fiscalização, justificativas técnicas, pareceres administrativos e jurídicos, planilhas de serviços e termos aditivos de contratos. A Tabela 2 ilustra a planilha de organização dos dados na etapa inicial do levantamento.

A análise dos dados possibilitou a identificação dos processos que atendiam ao escopo do trabalho, definindo o número de obras que foram analisadas. A Figura 4 ilustra o resultado da filtragem para obtenção da amostra.

Após a definição da amostra, seguiu-se a análise documental de cada contrato para classificar os custos adicionais nas categorias propostas na etapa de revisão da literatura.

\section{Análise documental}

Para realizar a classificação dos custos adicionais, optou-se pela análise textual com auxílio de programa de informática para apoio à análise de dados referentes às justificativas documentadas para cada contrato.

O intuito desta etapa foi sistematizar os textos das justificativas dos custos adicionais, identificando classes lexicais para que estas, posteriormente, pudessem ser interpretadas e relacionadas com a categorização de causas proposta na etapa anterior da revisão sistemática da literatura.

Buscou-se dessa forma a análise lexical (LAHLOU, 1994), uma vez que nesse tipo de análise os dados textuais são sistematizados a partir de identificação e organização do seu vocabulário para depois serem interpretados.

Tabela 2 - Parte da planilha de organização dos dados na etapa inicial do levantamento

\begin{tabular}{c|c|c|c|c|c|c|c|c|c|c|c}
\hline $\begin{array}{c}\mathbf{N}^{\circ} . \\
\text { Processo }\end{array}$ & $\begin{array}{c}\text { Objeto } \\
\text { Serviços/Obras }\end{array}$ & Situação & $\begin{array}{c}\text { Unidade/ } \\
\text { Órgão }\end{array}$ & $\begin{array}{c}\text { Valor da } \\
\text { Obra }\end{array}$ & Aditivos & $\begin{array}{c}\text { Área } \\
\left(\mathbf{m}^{2}\right)\end{array}$ & $\begin{array}{c}\text { Empresa } \\
\text { Contratada }\end{array}$ & $\begin{array}{c}\mathbf{N}^{\circ} \text {. } \\
\text { Contrato }\end{array}$ & $\begin{array}{c}\text { Data } \\
\text { Enazo de } \\
\text { Entrega }\end{array}$ & $\begin{array}{c}\text { Fiscal } \\
\text { resp. }\end{array}$ \\
\hline $\begin{array}{c}7634 / \mathrm{xx}- \\
21\end{array}$ & $\begin{array}{c}\text { Construção do } \\
\text { Centro de Aulas } \\
\text { B - Campus II }\end{array}$ & finalizado & $\begin{array}{c}\text { Unidade } \\
\text { A }\end{array}$ & $2.288 .999,48$ & $392.905,95$ & $2.494,00$ & $\begin{array}{c}\text { Construtora } \\
\text { Y Ltda. }\end{array}$ & $\begin{array}{c}131 / 08 \\
16 / 10 / 20 \\
\mathrm{xx}\end{array}$ & $\begin{array}{c}365 \\
\mathrm{X}\end{array}$ \\
\hline
\end{tabular}

Figura 4 - Filtragem para obtenção da amostra

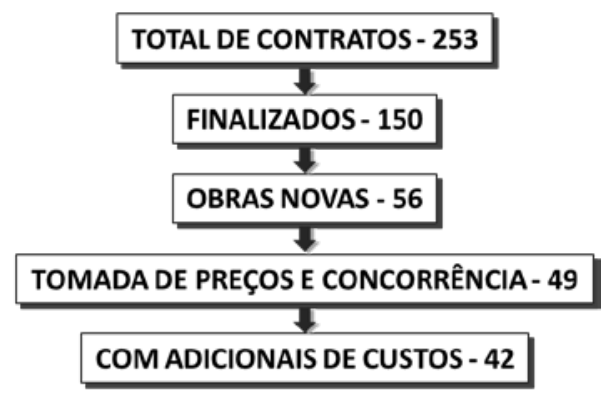


Outra justificativa para o uso da análise lexical foi o de evitar possível viés subjetivo na interpretação das causas dos custos adicionais, uma vez que as análises lexicais constituem uma família de técnicas que permitem explorações dos materiais textuais, viabilizando a construção de categorias naturais, a partir do uso de técnicas estatísticas no campo dos dados qualitativos.

Segundo Lahlou (1994) tais técnicas diminuem o subjetivismo nas análises dos textos, permitindo padronizações.

Para tal análise foi empregado o software francês IRAMUTEQ (Interface de $\mathrm{R}$ pour les Analyses Multidimensionnelles de Textes et de Questionnaires), que se ancora no ambiente estatístico do software R e na linguagem python (RATINAUD, 2009) para a análise textual.

O software IRAMUTEQ utiliza-se do mesmo algoritmo do software ALCESTE (Analyse Lexicale par Context d'un Ensemble de Segments de Texte) desenvolvido por Reinert (1990) para realizar análises estatísticas de textos, entre as quais a análise do tipo classificação hierárquica descendente (CHD), que oferece contextos (classes lexicais).

Uma etapa preliminar na análise textual refere-se à construção do corpus (no caso, os textos das justificativas). Os textos foram utilizados na sua forma original, transcritos para o software a partir dos documentos de cada contrato analisado. As análises foram conduzidas no software com base nos procedimentos detalhados em Salviati (2017), que trata da análise de dados textuais por meio do IRAMUTEQ.

$\mathrm{Na}$ análise lexical dos textos das justificativas para os adicionais de contrato, foram feitas as seguintes análises:

(a) lexicografia básica por cálculo de frequência de palavras;

(b) análises multivariadas englobando classificação hierárquica descendente (CHD). A análise CHD é baseada no ALCESTE (Analyse Lexicale par Context d'un Ensemble de Segments de Texte) (REINERT, 1990), visando obter classes de unidades de contexto elementares (UCE). As UCEs foram classificadas em função dos vocabulários de maior frequência e de valores de qui-quadrado mais elevados na classe. Todas as palavras que foram selecionadas possuíam $\mathrm{p}<0,001$, o que indica associação significativa. Essa análise visa obter classes de segmentos de texto que, ao mesmo tempo, apresentam vocabulário semelhante entre si, e vocabulário diferente dos segmentos de texto das outras classes;

(c) a partir dessas análises em matrizes, o software organiza a análise dos dados em uma representação gráfica (dendograma da CHD), que ilustra as relações entre as classes; e

(d) análise fatorial de correspondência feita a partir da CHD para gerar as palavras e variáveis associadas a cada uma das classes da CHD. Com base nas classes definidas, o programa calcula e fornece os segmentos de texto mais característicos de cada classe.

Cabe ressaltar que se buscou realizar uma compatibilização das classes geradas na CHD com a classificação dos fatores geradores dos aditivos contratuais proposta por Menezes (2013). Essa compatibilização ocorreu pelo fato de a pesquisa de Menezes ter sido precursora da investigação das causas de custos adicionais no âmbito da mesma autarquia da presente pesquisa.

O autor propôs duas vertentes para classificar as justificativas documentadas: falhas relacionadas anteriormente à contratação da obra (baseada no orçamento e projetos) e alterações que decorrem após a contratação da obra (por exemplo, devido a solicitações de usuários e que visam à manutenção).

As análises lexográficas geraram 6 classes de palavras. Nesta etapa foi conduzido um grupo focal, uma técnica de pesquisa qualitativa que coleta informações por meio de interações grupais (MORGAN, 1997). O propósito foi o de subsidiar a definição das classes de palavras a serem utilizadas para a análise das causas dos custos adicionais dos contratos de obras públicas.

O número de participantes foi de 12 pessoas, incluindo os gestores responsáveis pelo orçamento, contratação e fiscalização da autarquia. A escolha dos participantes ocorreu com base na aderência de seus perfis à temática central do estudo, tratando-se de uma seleção intencional. O roteiro das questões foi baseado na discussão sobre a concordância das classes de palavras geradas nas análises lexicais.

As 6 classes foram apresentadas aos participantes no formato ilustrado no Quadro 1.

Nesta etapa também foram analisados os custos adicionais e suas respectivas justificativas para cada contrato da amostra. Cada justificativa foi associada a uma classe de causa, conforme ilustrado no Quadro 2.

Posteriormente as 6 categorias de causas dos custos adicionais foram alinhadas com a taxonomia obtida da revisão da literatura. 


\section{Quadro 1 - Classificação para as causas dos aditivos apresentada aos participantes no grupo focal}

\begin{tabular}{|c|l|}
\hline \multirow{2}{*}{$\begin{array}{c}\text { Falhas de procedimentos } \\
\text { antes da contratação da obra }\end{array}$} & A1 (falha de orçamento e especificações) \\
\cline { 2 - 2 } & A2 (inconsistências de projetos) \\
\hline \multirow{2}{*}{$\begin{array}{c}\text { Alterações decorrentes de } \\
\text { necessidades após a } \\
\text { contratação da obra }\end{array}$} & B1 (alterações visando manutenção) \\
\cline { 2 - 2 } & B2 (alterações devido a solicitações dos usuários) \\
\cline { 2 - 2 } & B3 (alterações devido a fiscalização e projetistas) \\
\hline
\end{tabular}

Quadro 2 - Exemplo do registro de associação da categoria da causa ao adicional de custo

\begin{tabular}{|c|c|c|c|c|c|c|c|c|c|}
\hline $\begin{array}{c}\text { No. } \\
\text { Processo }\end{array}$ & $\begin{array}{c}\text { Objeto } \\
\text { Serviços }\end{array}$ & $\begin{array}{c}\text { Unidade } \\
\text { IÓrgão }\end{array}$ & Valor da Obra & Aditivos & $\begin{array}{c}\text { Empresa } \\
\text { Contratada }\end{array}$ & $\begin{array}{c}\text { No. } \\
\text { Contrato }\end{array}$ & Data & Justificativa apresentada & Classificação da causa \\
\hline $\begin{array}{c}023639 / x x \\
-15\end{array}$ & $\begin{array}{c}\text { Construção } \\
\text { dos } \\
\text { Laboratórios }\end{array}$ & $\begin{array}{c}\text { Parque } \\
\text { Tecnoló } \\
\text { gico }\end{array}$ & $3.177 .524,11$ & $932.827,89$ & $\begin{array}{c}\text { Construtora } \\
\text { X Ltda. }\end{array}$ & $\begin{array}{c}\text { Durante a execução da obra } \\
\text { foi viabilizado recurso para } \\
\text { instalação de um laboratório } \\
\text { no prédio, sendo assim o } \\
\text { coordenador da Escola fez } \\
\text { solicitação de alterações. }\end{array}$ & $\begin{array}{c}\text { B.2 - Atender adequações } \\
\text { dos projetos de arquitetura e } \\
\text { complementares, após a } \\
\text { contratação por necessidade } \\
\text { dos usuários }\end{array}$ \\
\hline
\end{tabular}

Com a definição das categorias de análise, foi feita uma nova análise lexicográfica considerando as justificativas transcritas. Essa análise da frequência de palavras para cada justificativa auxiliou na confirmação da classificação de cada aditivo registrado nos 42 processos em uma das categorias de causas.

\section{Análise do adicional de custo em cada contrato}

Após a identificação dos principais fatores que levaram à contratação de serviços adicionais, foi feita, em cada planilha de custos adicionais, a quantificação do impacto financeiro por adicional.

O impacto financeiro em relação aos itens dos orçamentos das obras foi analisado fazendo a leitura dos orçamentos iniciais, das propostas das empresas contratadas e das planilhas dos adicionais de custos contratuais. Todas as planilhas orçamentárias analisadas obedeciam à mesma padronização, conforme é ilustrada na Tabela 3 a planilha de um dos contratos analisados.

Os valores dos aditivos foram tabulados de acordo com a classificação das vertentes estabelecidas, o que permitiu identificar quais as categorias de causas tiveram maior impacto financeiro nos aditivos.

Para análise dos valores iniciais, valores contratados e valores dos aditivos foram consideradas as datas de realização do procedimento licitatório.

Foi feita a totalização dos valores contratados e aditivados por ano. Essa totalização permitiu a identificação dos impactos financeiros dos aditivos contratuais de cada um dos itens de serviço relacionados nas planilhas orçamentárias das obras contratadas.

Essa análise considerou o valor inicial do contrato e também o valor total de aditivos para cada um dos itens de serviço por ano. Para os resultados apresentados, esses valores monetários foram atualizados pelo Índice Nacional de Custo da Construção (INCC) (FUNDAÇÃO..., 2019) para o último mês de 2018. Entretanto, cabe ressaltar que, para a compreensão do impacto financeiro e da frequência de cada adicional de custo, como fatores de composição da análise de risco, priorizou-se a apresentação dos resultados em termos percentuais.

\section{Análise do impacto financeiro e frequência por categoria de causa}

Uma vez que o risco é a combinação do impacto com a probabilidade, para cada adicional de custo foram quantificados o seu impacto financeiro e seu impacto quantitativo, explicados a seguir.

Assim como preconiza a norma ISO/IEC 31010 (ABNT, 2012), para estimativas de probabilidades pode-se utilizar dados históricos para identificar situações que ocorreram no passado e, assim, ser possível a extrapolação da probabilidade de sua ocorrência no futuro. Dessa forma, a quantificação de custos adicionais foi utilizada para estimar a probabilidade de cada categoria de causa. 
Tabela 3 - Planilha de um dos contratos com a descrição dos itens principais orçamentários

\begin{tabular}{|c|c|c|c|c|}
\hline \multirow{2}{*}{ ITEM } & \multirow{2}{*}{ DESCRIÇÃO } & \multicolumn{3}{|c|}{ TP 14/20XX } \\
\hline & & INICIAL & CONTRATADO & ADITIVO \\
\hline 1.0 & SERVICOS INICIAIS / DESPESAS INICIAIS & $8.005,44$ & $7.344,08$ & $10.989,30$ \\
\hline 2.0 & INSTALACAO DO CANTEIRO & $3.619,20$ & $3.189,20$ & \\
\hline 3.0 & MOVIMENTO DE TERRA & $2.990,44$ & $3.829,22$ & $17.778,70$ \\
\hline 4.0 & SERVICOS GERAIS INTERNOS & & & \\
\hline 5.0 & INFRAESTRUTURA & $28.137,92$ & $19.449,36$ & $12.400,00$ \\
\hline 6.0 & SUPERESTRUTURA & $258.200,00$ & $203.693,02$ & $56.242,50$ \\
\hline 7.0 & PAREDES E PAINEIS & $31.654,32$ & $24.015,77$ & $10.513,80$ \\
\hline 8.0 & ESQUADRIAS & $15.126,40$ & $15.126,40$ & \\
\hline 9.0 & VIDROS & 938,51 & 938,51 & \\
\hline 10.0 & COBERTURA & $110.582,80$ & $82.082,97$ & 870,11 \\
\hline 11.0 & IMPERMEABILIZACAO & 786,79 & 788,79 & $1.643,21$ \\
\hline 12.0 & REVESTIMENTOS DE FORROS E PAREDES & $6.496,29$ & $7.394,61$ & \\
\hline 13.0 & RESERVA TECNICA & & & \\
\hline 14.0 & PISOS & $32.619,65$ & $35.190,05$ & \\
\hline 15.0 & INSTALACOES HIDROSSANITARIAS & $21.105,61$ & $17.878,01$ & $11.701,45$ \\
\hline 16.0 & INSTALACOES ELETRICAS & $102.889,39$ & $80.762,22$ & \\
\hline 17.0 & PINTURA & $11.157,10$ & $11.394,55$ & $4.173,66$ \\
\hline 18.0 & DIVERSOS & $10.677,61$ & $11.363,45$ & \\
\hline 19.0 & URBANIZACAO / PAVIMENTACAO & & & \\
\hline 20.0 & LIMPEZA & $1.947,42$ & $1.709,67$ & \\
\hline \multirow[t]{4}{*}{21.0} & ADMINISTRACAO DA OBRA & $25.200,00$ & $21.630,80$ & $9.409,40$ \\
\hline & Subtotal & $672.134,89$ & $547.780,68$ & $135.722,13$ \\
\hline & $\mathrm{BDI}$ & $22 \%$ & $22 \%$ & $22 \%$ \\
\hline & Total & $\begin{array}{r}\mathrm{RS} \\
820.004,57\end{array}$ & $\begin{array}{r}\mathrm{R} \$ \\
668.292,43\end{array}$ & $\begin{array}{r}\mathrm{R} \$ \\
165.581,00\end{array}$ \\
\hline
\end{tabular}

Para o impacto financeiro, a partir de cada planilha de custos adicionais foi feita a quantificação do impacto financeiro por adicional. Posteriormente foi feita a totalização do impacto financeiro para cada categoria de causa.

Em outra análise comparativa final, quanto ao impacto financeiro, buscou-se entender o percentual de impacto de cada item do orçamento em relação ao total de aditivos e em relação ao contrato inicial. Essa análise é complementar à análise do impacto financeiro, cujo foco está no impacto por categoria de causa. A análise por item orçamentário pode contribuir para futuras ações de mitigação do risco de custos adicionais, considerando as características particulares de cada contrato que podem diferir em inúmeros aspectos, como em termos de tecnologias construtivas e porte da obra.

Posteriormente foi feita uma análise comparativa em termos percentuais dos impactos financeiros e quantitativos para cada classe de custos adicionais.

A tabulação dos resultados permitiu uma visualização dos principais fatores geradores de aditivos de serviços quanto à incidência e ao impacto no custo total das obras, estes são os indicadores que permitem o cálculo do risco associado a cada categoria de causa.

\section{Análise das categorias de causa por meio do índice de risco}

Um índice de criticidade de risco foi calculado, considerando o impacto financeiro e a probabilidade baseada na frequência de cada categoria de causa. O cálculo do índice derivou da construção de uma matriz de probabilidade/consequência que consiste no meio de combinar classificações qualitativas ou semiquantitativas de consequências e probabilidade com o intuito de produzir uma classificação de risco, conforme orienta a NBR ISO/IEC 31010 (ABNT, 2012).

As entradas do processo na matriz de risco são escalas personalizadas de consequência (ou impacto) e probabilidade. Foram consideradas escalas de 4 pontos para ambas as entradas: baixo, moderado, alto e muito alto. Seguiu-se a recomendação da NBR ISO/IEC 31010 (ABNT, 2012) para utilizar escalas baseadas em um contexto de confiabilidade, uma vez que o estudo já dispunha das taxas de frequência (que permitiu criar a escala de probabilidade) bem como os dados dos impactos financeiros (que permitiu criar a escala do impacto) para cada uma das causas dos custos adicionais. Como recomendado pela referida norma, os níveis de risco 
podem ser definidos pela equipe envolvida no processo. Para o estudo de caso, os níveis de impacto e frequência/probabilidade foram definidos considerando as faixas:
(a) até $10 \%$ (baixo);
(b) até $25 \%$ (moderado);
(c) até $50 \%$ (alto); e
(d) acima de $50 \%$ (muito alto).

\section{Quadro 3 - Categorias para análise do risco relacionado aos custos adicionais em empreendimentos} (Continua...)

\begin{tabular}{|c|c|c|c|c|c|}
\hline & CATEGORIA & $\begin{array}{c}\text { FONTES DE } \\
\text { VULNERABILIDADE }\end{array}$ & FONTE DE RISCO & $\begin{array}{l}\text { EVENTO DE } \\
\text { RISCO } \\
\end{array}$ & PESQUISAS RELACIONADAS À CATEGORIA \\
\hline 1 & Projeto & $\begin{array}{l}\text { Falta de } \\
\text { coordenação, } \\
\text { deficiências de } \\
\text { qualificação dos } \\
\text { envolvidos no } \\
\text { processo projetual, } \\
\text { falta de planejamento } \\
\text { e controle, falta de } \\
\text { conhecimento do } \\
\text { mercado e das } \\
\text { necessidades dos } \\
\text { clientes }\end{array}$ & $\begin{array}{l}\text { Mudança de escopo, Projeto } \\
\text { de baixa qualidade (não } \\
\text { atendimento às normas, falta } \\
\text { de informações, } \\
\text { discrepâncias entre } \\
\text { desenhos, soluções } \\
\text { incorretas), falta de } \\
\text { construtibilidade, problemas } \\
\text { de especificações e } \\
\text { detalhamentos, atrasos em } \\
\text { aprovação ou elaboração, } \\
\text { ausência de compatibilização, }\end{array}$ & $\begin{array}{l}\text { Alterações nos } \\
\text { serviços em } \\
\text { execução } \\
\text { (envolvendo mão de } \\
\text { obra, material, } \\
\text { equipamentos, } \\
\text { métodos), atrasos }\end{array}$ & $\begin{array}{l}\text { Arditi, Akan e Gurdamar (1985); Elinwa e Buba } \\
\text { (1993); Love et al. (2002); Hsieh, Lu e Wu (2004); } \\
\text { Magnussen e Olsson (2006); Oladapo (2007); Dada e } \\
\text { Jagboro (2007); Love et al. (2010); Ahsan e Gunawan } \\
\text { (2010); Ramabodu e Verster (2010); Doloi (2011); } \\
\text { Chan et al. (2011); Baloyi e Bekker (2011); Fidan et al. } \\
\text { (2011); Ramanathan, Narayanan e Idrus (2012); } \\
\text { Ahiaga-Dagbui e Smith (2013); Cheng (2014); } \\
\text { Dominic e Smith (2014); Wanjari e Dobariya (2016); } \\
\text { Famiyeh et al. (2017); Niazi e Painting (2017); Keng, } \\
\text { Mansor e Ching (2018); Kim et al. (2018); Amusan et } \\
\text { al. (2018) }\end{array}$ \\
\hline 2 & $\begin{array}{l}\text { Mudanças } \\
\text { nos } \\
\text { requisitos } \\
\text { dos clientes }\end{array}$ & $\begin{array}{l}\text { Falta de clareza dos } \\
\text { objetivos do cliente, } \\
\text { ausência de } \\
\text { informações sobre } \\
\text { manutenibilidade, } \\
\text { deficiência na } \\
\text { comunicação com os } \\
\text { clientes }\end{array}$ & Solicitações não previstas & $\begin{array}{l}\text { Alterações nos } \\
\text { serviços em } \\
\text { execução } \\
\text { (envolvendo mão de } \\
\text { obra, material, } \\
\text { equipamentos, } \\
\text { métodos), atrasos }\end{array}$ & $\begin{array}{l}\text { Oladapo (2007); Enshassi, Al-Najjar e Akumaraswamy } \\
\text { (2009); Fidan et al. (2011); Baloyi e Bekker (2011); } \\
\text { Ramanathan, Narayanan e Idrus (2012); Alinaitwe, } \\
\text { Apolot e Tindiwensi (2013); Rosenfeld (2013); } \\
\text { Famiyeh et al. (2017); Niazi e Painting (2017); Keng, } \\
\text { Mansor e Ching (2018); Gunduz e Maki (2018); } \\
\text { Amusan et al. (2018) }\end{array}$ \\
\hline 3 & $\begin{array}{l}\text { Questões } \\
\text { sistêmicas }\end{array}$ & $\begin{array}{l}\text { Impostos, política de } \\
\text { juros, inflação, } \\
\text { problemas } \\
\text { trabalhistas e de } \\
\text { seguros, flutuação } \\
\text { dos preços de } \\
\text { materiais, } \\
\text { equipamentos e } \\
\text { salários, burocracias } \\
\text { do sistema }\end{array}$ & $\begin{array}{l}\text { Alterações dos preços dos } \\
\text { insumos }\end{array}$ & $\begin{array}{l}\text { Aumento do custo } \\
\text { dos insumos e dos } \\
\text { serviços em } \\
\text { execução }\end{array}$ & $\begin{array}{l}\text { Arditi, Akan e Gurdamar (1985); Okpala e Aniekwu } \\
\text { (1988); Elinwa e Buba (1993); Mansfield, Ugwu e } \\
\text { Doran (1994); Magnussen e Olsson (2006); Enshassi, } \\
\text { Al-Najjar e Akumaraswamy (2009); Ahsan e Gunawan } \\
\text { (2010); Fidan et al. (2011); Baloyi e Bekker (2011); } \\
\text { Chan et al. (2011); Ramanathan, Narayanan e Idrus } \\
\text { (2012); Ahiaga-Dagbui e Smith (2013); Mahamid e } \\
\text { Dmaidi (2013); Alinaitwe, Apolot e Tindiwensi (2013); } \\
\text { Niazi e Painting (2017); Famiyeh et al. (2017); Keng, } \\
\text { Mansor e Ching (2018); Kim et al. (2018); Amusan et } \\
\text { al. (2018) }\end{array}$ \\
\hline 4 & $\begin{array}{l}\text { Planeja- } \\
\text { mente } \\
\text { financeiro } \\
\text { ineficiente }\end{array}$ & $\begin{array}{l}\text { Ausência de } \\
\text { informações ou } \\
\text { qualificação dos } \\
\text { envolvidos }\end{array}$ & $\begin{array}{l}\text { Preço inferior ao estimado, } \\
\text { ausência de monitoramento } \\
\text { dos custos em execuccão, } \\
\text { ausência de estudos de } \\
\text { viabilidade }\end{array}$ & $\begin{array}{l}\text { Aumento do custo } \\
\text { dos insumos e dos } \\
\text { serviços em } \\
\text { execução }\end{array}$ & $\begin{array}{l}\text { Elinwa e Buba (1993); Mansfield, Ugwu e Doran } \\
\text { (1994); Creedy (2006); Magnussen e Olsson (2006); } \\
\text { Dada e Jagboro (2007); Ahsan e Gunawan (2010); } \\
\text { Ramabodu e Verster (2010); Doloi (2011); Doloi et al. } \\
\text { (2012); Ramanathan, Narayanan e Idrus (2012); } \\
\text { Mahamid e Dmaidi (2013); Ahiaga-Dagbui e Smith } \\
\text { (2013); Cheng (2014); Shehu, Endut e Akintoye } \\
\text { (2014); Wanjari e Dobariya (2016); Niazi e Painting } \\
\text { (2017); Keng, Mansor e Ching (2018); Amusan et al. } \\
\text { (2018) }\end{array}$ \\
\hline 5 & $\begin{array}{l}\text { Má gestão } \\
\text { do contrato }\end{array}$ & $\begin{array}{l}\text { Ausência de } \\
\text { informações ou } \\
\text { qualificação dos } \\
\text { envolvidos }\end{array}$ & $\begin{array}{l}\text { Erros e omissões, ineficiência } \\
\text { da fiscalização, baixa } \\
\text { qualidade da documentação } \\
\text { do empreendimento, } \\
\text { subestimação de prazo ou } \\
\text { custo }\end{array}$ & $\begin{array}{l}\text { Aumento do prazo e } \\
\text { custo dos serviços } \\
\text { em execução }\end{array}$ & $\begin{array}{l}\text { Okpala e Aniekwu (1988); Elinwa e Buba (1993); } \\
\text { Mansfield, Ugwu e Doran (1994); Baloi e Price (2003); } \\
\text { Creedy (2006); Doloi (2011); Baloyi e Bekker (2011); } \\
\text { Doloi et al. (2012); Ramanathan, Narayanan e Idrus } \\
\text { (2012); Alinaitwe, Apolot e Tindiwensi (2013); } \\
\text { Mahamid e Dmaidi (2013); Cheng (2014); Wanjari e } \\
\text { Dobariya (2016); Famiyeh et al. (2017); Keng, Mansor } \\
\text { e Ching (2018); Amusan et al. (2018) }\end{array}$ \\
\hline 6 & $\begin{array}{l}\text { Saúde e } \\
\text { segurança }\end{array}$ & $\begin{array}{l}\text { Ausência de medidas } \\
\text { preventivas } \\
\text { relacionadas à saúde } \\
\text { e segurança dos } \\
\text { trabalhadores }\end{array}$ & $\begin{array}{l}\text { Problemas de saúde e } \\
\text { segurança dos trabalhadores }\end{array}$ & $\begin{array}{l}\text { Baixa produtividade, } \\
\text { atrasos, } \\
\text { absenteísmo, } \\
\text { acidentes }\end{array}$ & $\begin{array}{l}\text { Arditi, Akan e Gurdamar (1985); Ramanathan, } \\
\text { Narayanan e Idrus (2012); Cheng (2014) }\end{array}$ \\
\hline
\end{tabular}


Quadro 3 - Categorias para análise do risco relacionado aos custos adicionais em empreendimentos (continuação)

\begin{tabular}{|c|c|c|c|c|c|}
\hline & CATEGORIA & $\begin{array}{c}\text { FONTES DE } \\
\text { VULNERABILIDADE }\end{array}$ & FONTE DE RISCO & $\begin{array}{l}\text { EVENTO DE } \\
\text { RISCO }\end{array}$ & PESQUISAS RELACIONADAS Ȧ CATEGORIA \\
\hline 7 & $\begin{array}{l}\text { Condições } \\
\text { locais e } \\
\text { ambientais } \\
\text { não } \\
\text { previstas }\end{array}$ & $\begin{array}{l}\text { Aspectos } \\
\text { relacionados ao solo, } \\
\text { infraestrutura, clima, } \\
\text { entre outros } \\
\text { ambientais não } \\
\text { contemplados nos } \\
\text { projetos }\end{array}$ & $\begin{array}{l}\text { Alteração de escopo e } \\
\text { projetos }\end{array}$ & $\begin{array}{l}\text { Alterações nos } \\
\text { serviços em } \\
\text { execução, atrasos }\end{array}$ & $\begin{array}{l}\text { Arditi, Akan e Gurdamar (1985); Dada e Jagboro } \\
\text { (2007); Doloi (2011); Chan et al. (2011); Fidan et al. } \\
\text { (2011); Ramanathan, Narayanan e Idrus (2012); } \\
\text { Mahamid e Dmaidi (2013); Cheng (2014); Dominic e } \\
\text { Smith (2014); Wanjari e Dobariya (2016); Keng, } \\
\text { Mansor e Ching (2018); Kim et al. (2018); Amusan et } \\
\text { al. (2018) }\end{array}$ \\
\hline 8 & $\begin{array}{l}\text { Erros } \\
\text { orçamen- } \\
\text { tários }\end{array}$ & $\begin{array}{l}\text { Ausência de } \\
\text { informações ou } \\
\text { qualificação dos } \\
\text { envolvidos }\end{array}$ & $\begin{array}{l}\text { Estimativa errada da } \\
\text { quantidade de serviço, de } \\
\text { mão de obra ou } \\
\text { equipamentos; método } \\
\text { construtivo realizado diferente } \\
\text { do orçado; erros no cálculo de } \\
\text { impostos; erros na definição } \\
\text { da composição de custos }\end{array}$ & $\begin{array}{l}\text { Aumento do custo } \\
\text { dos insumos e dos } \\
\text { serviços em } \\
\text { execução }\end{array}$ & $\begin{array}{l}\text { Elinwa e Buba (1993); Enshassi, Al-Najjar e } \\
\text { Akumaraswamy (2009); Baloyi e Bekker (2011); Chan } \\
\text { et al. (2011); Ahiaga-Dagbui e Smith (2013); Keng, } \\
\text { Mansor e Ching (2018); Kim et al. (2018) }\end{array}$ \\
\hline 9 & $\begin{array}{l}\text { Problemas } \\
\text { de disponi- } \\
\text { bilidade dos } \\
\text { materiais e } \\
\text { mão de obra } \\
\text { previstos }\end{array}$ & $\begin{array}{l}\text { Escassez de } \\
\text { materiais e mão de } \\
\text { obra, ausência de } \\
\text { treinamento e } \\
\text { qualificação dos } \\
\text { funcionários }\end{array}$ & $\begin{array}{l}\text { Baixa qualificação dos } \\
\text { funcionários, problemas de } \\
\text { gestão com subempreiteiros e } \\
\text { fornecedores }\end{array}$ & $\begin{array}{l}\text { Baixa produtividade, } \\
\text { absenteísmo, } \\
\text { atrasos, baixa } \\
\text { qualidade dos } \\
\text { serviços }\end{array}$ & $\begin{array}{l}\text { Okpala e Aniekwu (1988); Elinwa e Buba (1993); } \\
\text { Mansfield, Ugwu e Doran (1994); Sambasivan e Soon } \\
\text { (2007); Dada e Jagboro (2007); Fidan et al. (2011); } \\
\text { Baloyi e Bekker (2011); Ramanathan, Narayanan e } \\
\text { Idrus (2012); Cheng (2014); Keng, Mansor e Ching } \\
\text { (2018) }\end{array}$ \\
\hline 10 & $\begin{array}{c}\text { Ineficiência } \\
\text { da gestão da } \\
\text { obra }\end{array}$ & $\begin{array}{l}\text { Erros de } \\
\text { planejamento e } \\
\text { controle por parte da } \\
\text { gestão }\end{array}$ & $\begin{array}{l}\text { Falhas no controle da } \\
\text { qualidade de materiais e } \\
\text { serviços, emprego de } \\
\text { técnicas inadequadas, falta } \\
\text { de treinamento, logística } \\
\text { ineficiente, condições } \\
\text { inadequadas do canteiro, } \\
\text { erros de comunicação, } \\
\text { identificação ineficiente de } \\
\text { responsabilidades, falta de } \\
\text { gerenciamento de } \\
\text { subempreiteiros, ineficiência } \\
\text { em avaliações de } \\
\text { desempenho, erros de } \\
\text { estimativa de prazo e custo }\end{array}$ & $\begin{array}{l}\text { Alteração de } \\
\text { cronograma, baixa } \\
\text { produtividade, } \\
\text { diminuição da } \\
\text { qualidade dos } \\
\text { serviços, } \\
\text { retrabalhos, perdas, } \\
\text { desperdícios }\end{array}$ & $\begin{array}{l}\text { Love et al. (2002); Dada e Jagboro (2007); Fidan et al } \\
\text { (2011); Ramanathan, Narayanan e Idrus (2012); } \\
\text { Ahiaga-Dagbui e Smith (2013); Mahamid e Dmaidi } \\
\text { (2013); Alinaitwe, Apolot e Tindiwensi (2013); Cheng } \\
\text { (2014); Rosenfeld (2014); Wanjari e Dobariya (2016); } \\
\text { Keng, Mansor e Ching (2018); Gunduz e Maki (2018); } \\
\text { Kim et al. (2018); Amusan et al. (2018) }\end{array}$ \\
\hline
\end{tabular}

\section{Resultados e discussões}

Seguem os resultados e discussões que abrangem a análise das causas dos aditivos contratuais.

\section{Proposta de categorização baseada na taxonomia do risco por meio da revisão sistemática da literatura}

O Quadro 3 apresenta a nova categorização proposta para análise das causas de custos adicionais, considerando uma nova taxonomia dos termos relacionados ao risco. As pesquisas referenciadas em cada grupo indicam que a categoria foi citada como causa do potencial para os custos adicionais em empreendimentos.

A Figura 5 apresenta a quantificação de publicações por ano para cada uma das categorias estabelecidas pela RSL.

De todas as categorias de causas para os custos adicionais, os itens relacionados ao projeto foram os mais citados na literatura pesquisada, seguidos por questões sistêmicas e pelo planejamento financeiro ineficiente que inclui o monitoramento deficiente dos custos ao longo da execução do empreendimento.

A nova categorização busca suprir a proposta de uma classificação que abrange fatores de vulnerabilidade, fontes e eventos de risco de modo a facilitar estudos investigativos a respeito das causas que geram o adicional de custos em empreendimentos. 


\section{Classificação das causas para contratação de serviços adicionais pela análise lexical}

A análise de lexicografia básica considerando todas as justificativas documentadas confirmou as maiores frequências das palavras “obra”, "alteração”, “projeto” e "necessidade”, conforme pode ser visualizada na tela do software Iramuteq na Figura 6.

Para análise textual e apresentação das classes referentes às justificativas dos 42 contratos analisados, o corpus foi dividido em 2 subcorpus. De um subcorpus obteve-se a classe 6, que concentrou 12,5\% das UCEs. Do outro subcorpus, derivaram as demais classes e repartições. A Figura 7 ilustra a classificação hierárquica descendente com o dendograma das classes.

As seis classes geradas na análise baseada no ALCESTE (Analyse Lexicale par Context d'un Ensemble de Segments de Texte) sugerem a formação da base das categorias das justificativas analisadas.

A Figura 8 ilustra parte da análise fatorial de correspondência feita a partir da CHD para gerar as palavras e variáveis associadas a cada uma das classes da CHD.

As classes geradas pelas análises lexográficas foram analisadas pelos gestores responsáveis pelo orçamento, contratação e fiscalização da autarquia por meio do grupo focal. Posteriormente foram geradas as categorias de causas dos custos adicionais e alinhadas com a taxonomia obtida da revisão da literatura.

Essa análise resultou na categorização de causas ilustrada na Figura 9.

Figura 5 - Publicações por ano por categoria de causa

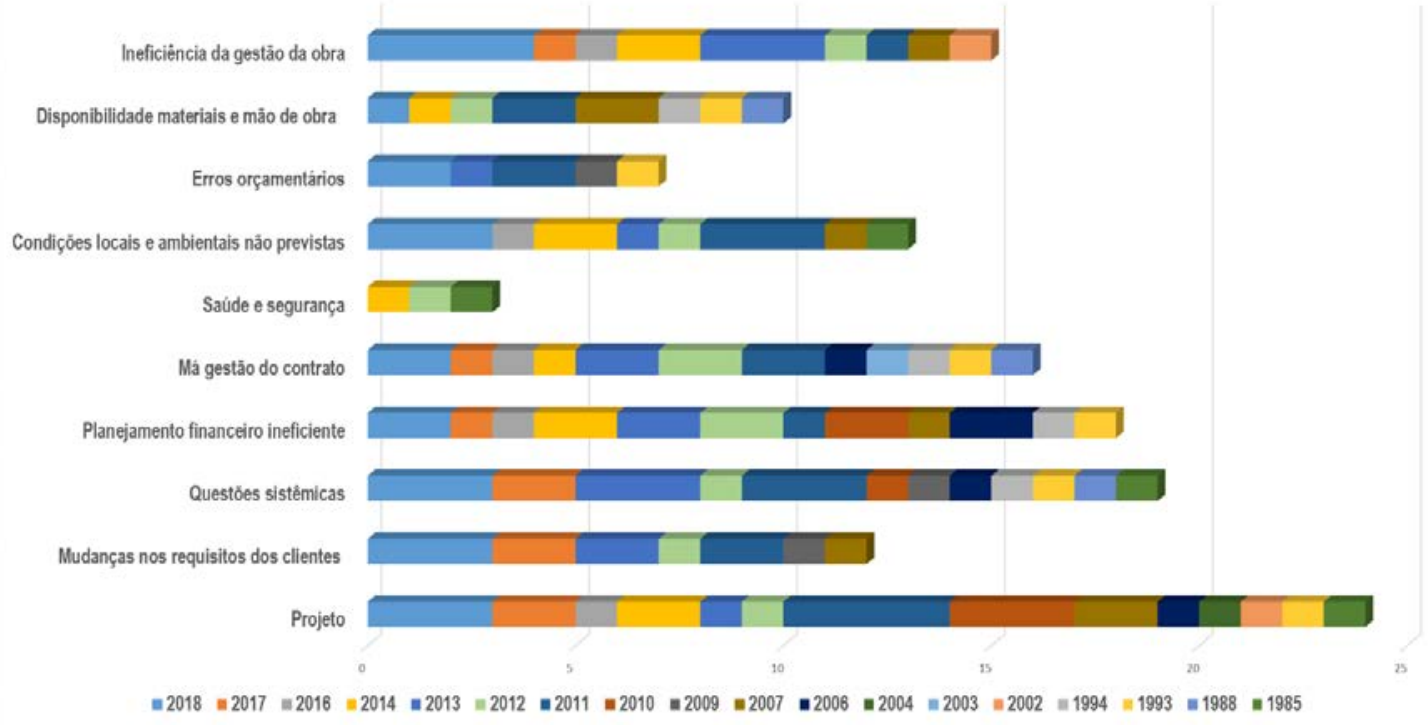

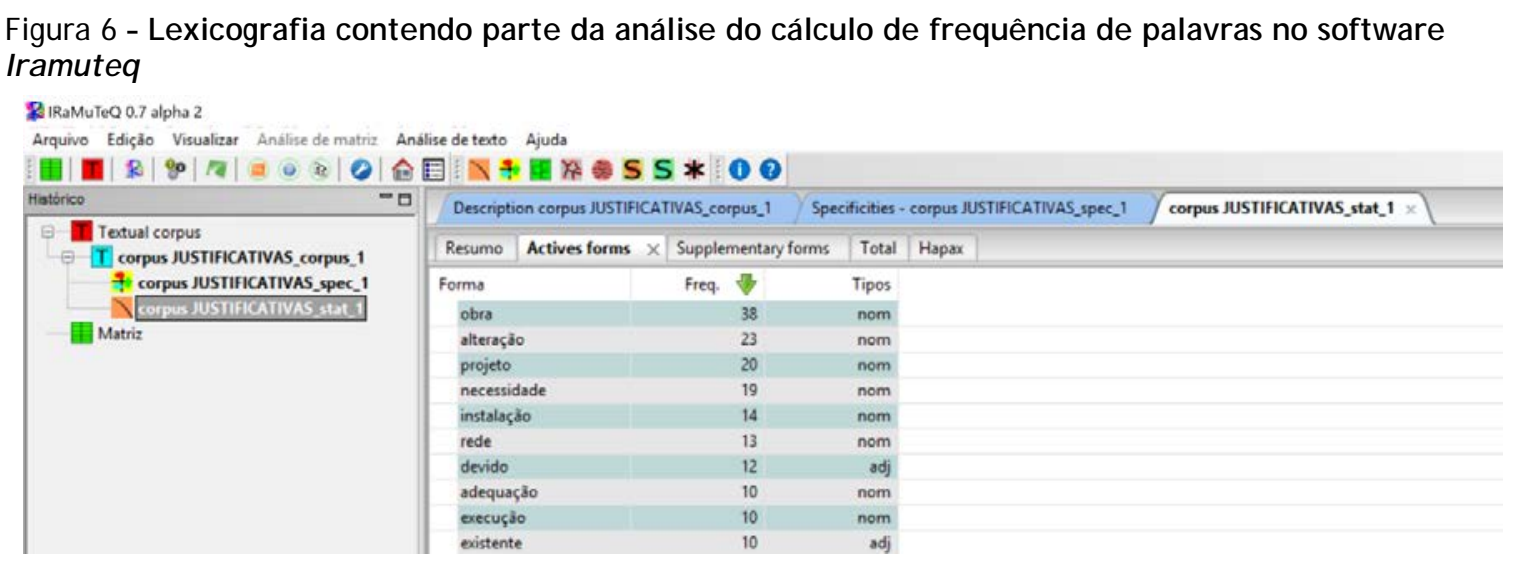


Figura 7 - Dendograma de classes originado da classificação hierárquica descendente

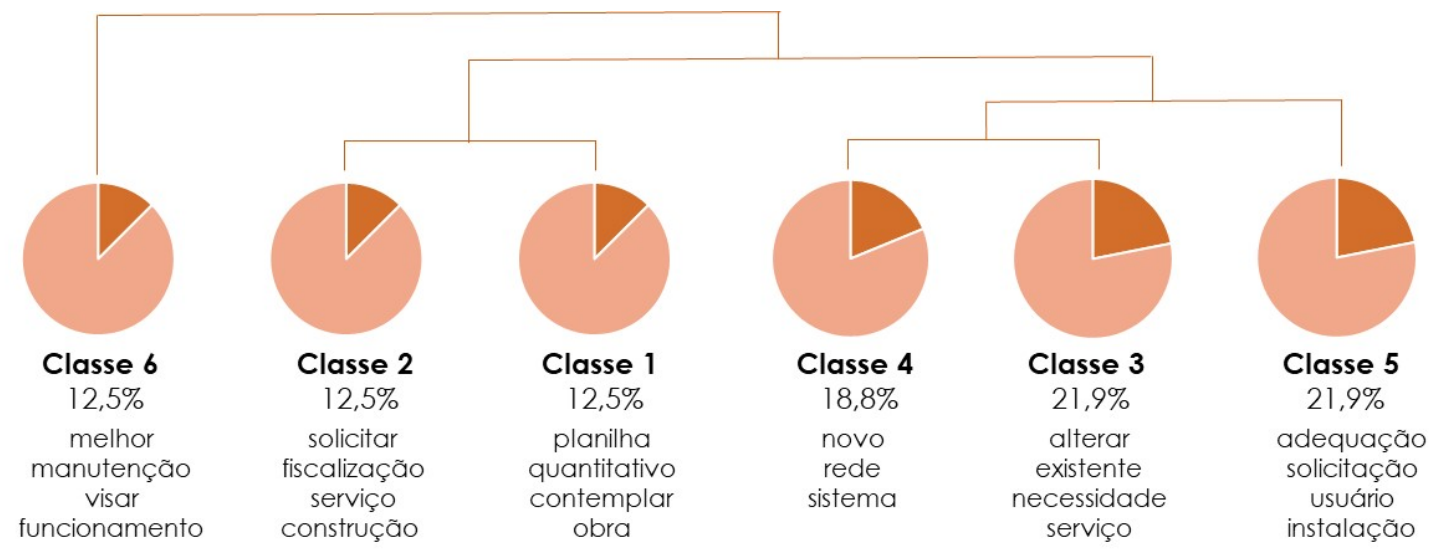

Figura 8 - Análise fatorial de correspondência a partir da classificação hierárquica descendente

\begin{tabular}{|c|c|c|c|c|c|c|c|}
\hline \multicolumn{8}{|c|}{ Classificaşào - Justificativas U_corpus_1 X } \\
\hline \multicolumn{8}{|c|}{ 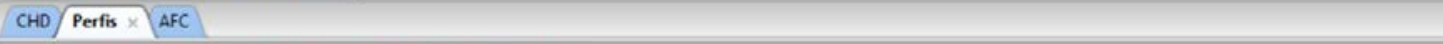 } \\
\hline $\begin{array}{l}1 \text { Classe } 1 \\
4 / 32 \\
12.5 \%\end{array}$ & $\begin{array}{l}2 \text { Classe } 2 \\
4 / 32 \\
12.5 \%\end{array}$ & $\begin{array}{l}3 \text { Classe } 3 \\
7 / 32 \\
21.88 \%\end{array}$ & $\begin{array}{l}4 \text { Classe } 4 \\
6 / 32 \\
18.75 \%\end{array}$ & $\begin{array}{l}5 \text { Classe } 5 \\
7 / 32 \\
21.88 \%\end{array}$ & $\begin{array}{l}6 \text { Classe } 6 \\
4 / 32 \\
12.5 \%\end{array} \times$ & & + \\
\hline n... 숩 & eff. s.t. & eff. total & pource & itage & Type & forme & p \\
\hline 0 & 4 & 4 & & 100.0 & 32.0 & melhor & $<0,0001$ \\
\hline 1 & 3 & 4 & & 75.0 & 16.33 & manutençăo & $<0,0001$ \\
\hline 2 & 3 & 4 & & 75.0 & 16.33 & visar & $<0,0001$ \\
\hline
\end{tabular}

Figura 9 - Classificação das causas para os aditivos contratuais do estudo de caso sob a ótica da gestão de risco

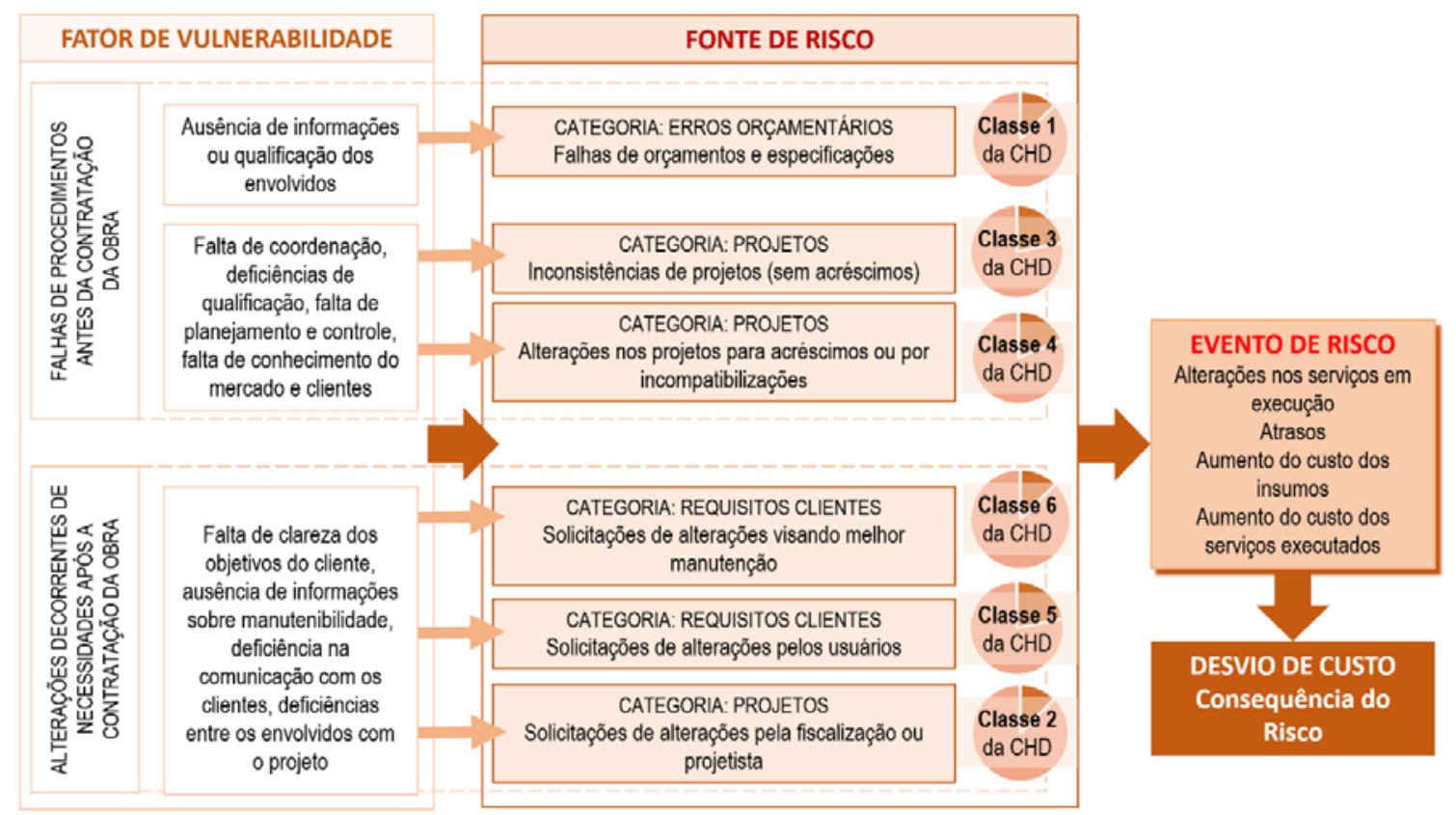

Cada classe gerada no dendograma, apresentado na Figura 7, foi atribuída a uma descrição como, por exemplo, a classe 6, que apresentou no dendograma as conexões entre as palavras "melhor”, "manutenção", "visar”, "funcionamento", resultando na proposta de classe descrita como "alterações visando melhor manutenção". Essa descrição foi enquadrada na categoria "requisitos dos clientes”, definida na categorização resultante da literatura (apresentada no Quadro 3). Os fatores de vulnerabilidade atribuídos às classes também correspondem às suas respectivas categorias definidas no Quadro 3. 
Para o estudo de caso foram levantadas 3 fontes de risco referentes às categorias de erros orçamentários, projeto e requisitos dos clientes.

Para adequação ao dendograma gerado na CHD, foram propostas 6 classes de causas, abrangendo 1 classe para os erros orçamentários relativos às falhas anteriores à contratação da obra, 2 classes relativas às falhas relacionadas aos requisitos dos clientes em fase posterior à contratação da obra e 3 classes envolvendo os projetos (2 classes abrangendo falhas de inconsistências ou incompatibilizações e necessidades de acréscimos detectadas anteriormente à obra e 1 classe relativa às solicitações de alterações provenientes da fiscalização ou projetistas após a contratação da obra).

A nova classificação atendeu à taxonomia proposta, estabelecendo de forma sistemática as fontes de vulnerabilidade e as fontes de risco (que permitirão proceder a uma análise futura da causa-raiz), além dos eventos de risco que geraram por consequência o adicional de custo.

Com a definição das categorias de análise, foi feita uma nova análise lexicográfica por justificativas transcritas, conforme ilustrada na Figura 10.

Essa análise da frequência de palavras para cada justificativa auxiliou na confirmação da classificação de cada aditivo registrado nos 42 processos em uma das categorias de causas definidas, de modo a permitir a análise quantitativa dos impactos financeiros por causa.

\section{Distribuição das causas dos aditivos por quantidade e valores financeiros}

O gráfico apresentado na Figura 11 ilustra a preponderância das causas relativas à necessidade de alterações surgidas após a contratação da obra, principalmente por pedidos da fiscalização ou dos projetistas.

Para cálculo do impacto financeiro referente aos itens estudados nos contratos foi considerado o valor total de acréscimo de R \$ 8.527.770,48, que corresponde à média de 21,01\% de acréscimo em relação ao montante do valor contratado para as obras analisadas. O desvio padrão em relação aos aditivos foi de 0,14.

Do total dos aditivos das obras analisadas, as alterações provenientes das fiscalizações e dos projetistas corresponderam à metade do total de aditivos contratados e também correspondem à metade do valor total gasto em aditivos. A segunda justificativa mais utilizada para realização de contratações adicionais é referente a alterações devido às solicitações dos usuários (com quantitativo e impacto similares em torno de 20\%).

Cerca de 85\% dos valores dos aditivos são provenientes de solicitações que ocorrem após a contratação da obra provenientes dos usuários ou projetistas e fiscais de obras, permitindo inferir sobre a necessidade de ajuste das informações relativas aos objetivos dos usuários e adequação do projeto na etapa anterior à contratação.

Esse resultado também é afetado pelos longos prazos existentes entre a preparação da documentação para as licitações e o início da execução das obras, geralmente comum no âmbito das obras públicas.

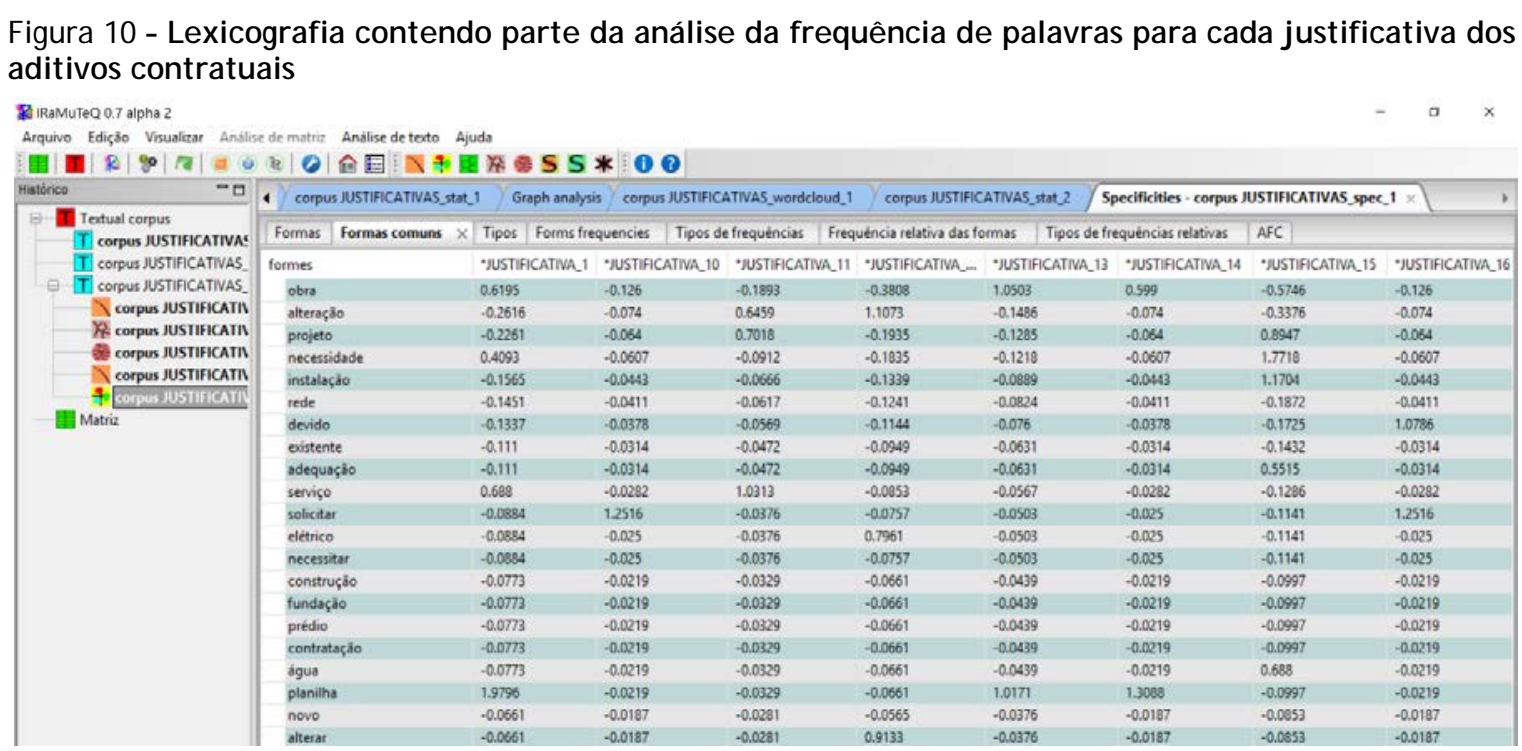


Figura 11 - Distribuição das causas dos aditivos por quantidade e valores financeiros

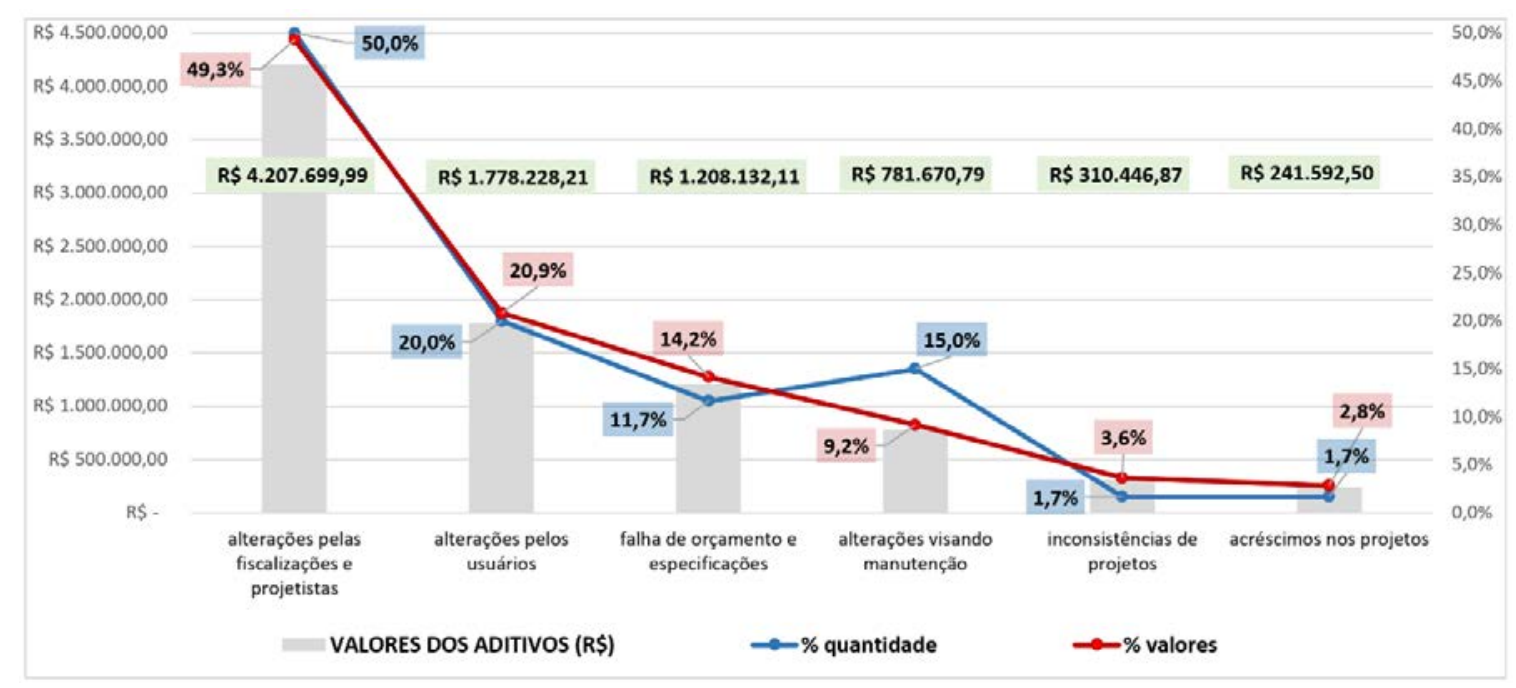

\section{Resultado em relação ao impacto financeiro por itens do orçamento}

A Figura 12 ilustra a distribuição do impacto financeiro dos aditivos por itens do orçamento.

Percebe-se que não necessariamente os itens que têm maior impacto em relação ao total de aditivos são os itens que mais extrapolaram em relação ao seu valor de contrato. Dos valores aditivados, o maior impacto financeiro ocorreu no item instalações elétricas, seguido pelo item de superestrutura. A contratação de aditivos decorre do grande número de alterações solicitadas após a contratação da obra pela fiscalização ou pelos projetistas, além do fato desses itens serem comumente representativos em obras de construção civil.

Os itens que superam 30\% o seu valor de contrato são: movimentação de terra, administração da obra, impermeabilização, paredes e painéis e infraestrutura. Em várias obras foi apontada como justificativa para contratação adicional a mudança do local da obra, dentro do terreno, ocasionando alterações de níveis e implantação dessas edificações, as quais foram solicitadas pelos usuários, fiscais ou projetistas. O impacto financeiro da administração da obra geralmente é consequencial dos aditivos de prazo.

\section{Análise comparativa dos impactos quantitativos e financeiros dos aditivos}

Uma análise comparativa foi feita para cada causa dos aditivos, em relação ao seu impacto quantitativo e seu impacto financeiro, conforme pode ser visualizada na Figura 13.

As causas relacionadas aos projetos destacam-se em relação às demais, englobando as falhas detectadas anteriormente à contratação da obra e, em especial, às alterações que são solicitadas por fiscais ou projetistas para adequação dos projetos.

A justificativa de alteração surgida após a contratação da obra por necessidade da fiscalização ou dos projetistas apresentou maior ocorrência e maior impacto financeiro. Nota-se pelo gráfico da Figura 14 que a quantidade de justificativas guarda relação proporcional com o impacto financeiro em todas as justificativas analisadas.

\section{Análise das categorias de causa por meio do índice de risco}

Anterior à construção da matriz de risco para as causas analisadas na pesquisa, foi feita a análise gráfica da Figura 15 para comparar os valores de obra e aditivo para cada um dos 60 aditivos levantados nos 42 processos, classificando-os segundo as categorias de fonte de risco.

A análise gráfica permite compreender a preponderância dos aditivos relacionados aos projetos sobre os demais. Os requisitos dos clientes também correspondem a um percentual significativo das justificativas levantadas para os custos adicionais. 
Figura 12 - Distribuição do impacto financeiro dos aditivos por itens do orçamento

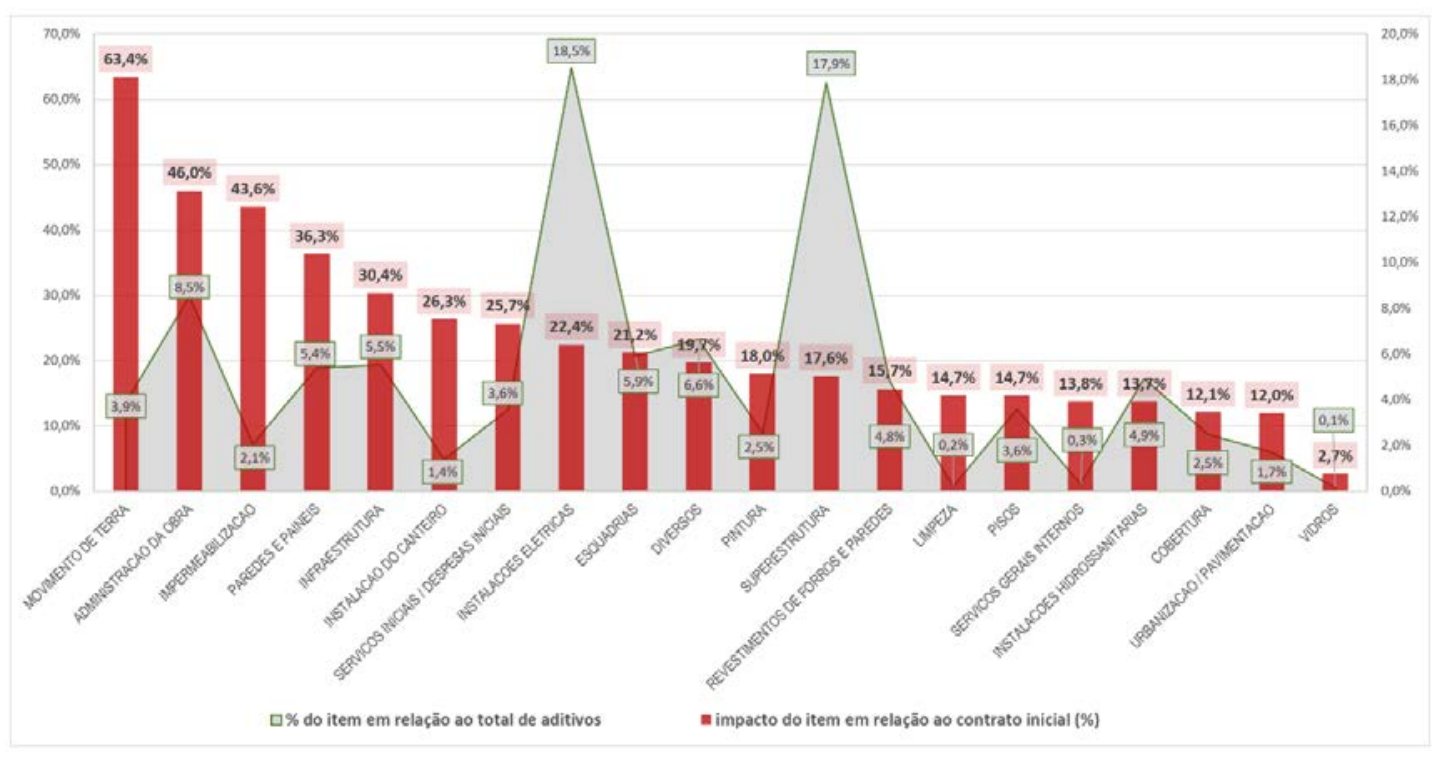

Figura 13 - Análise comparativa dos impactos quantitativos e financeiros dos aditivos por causa

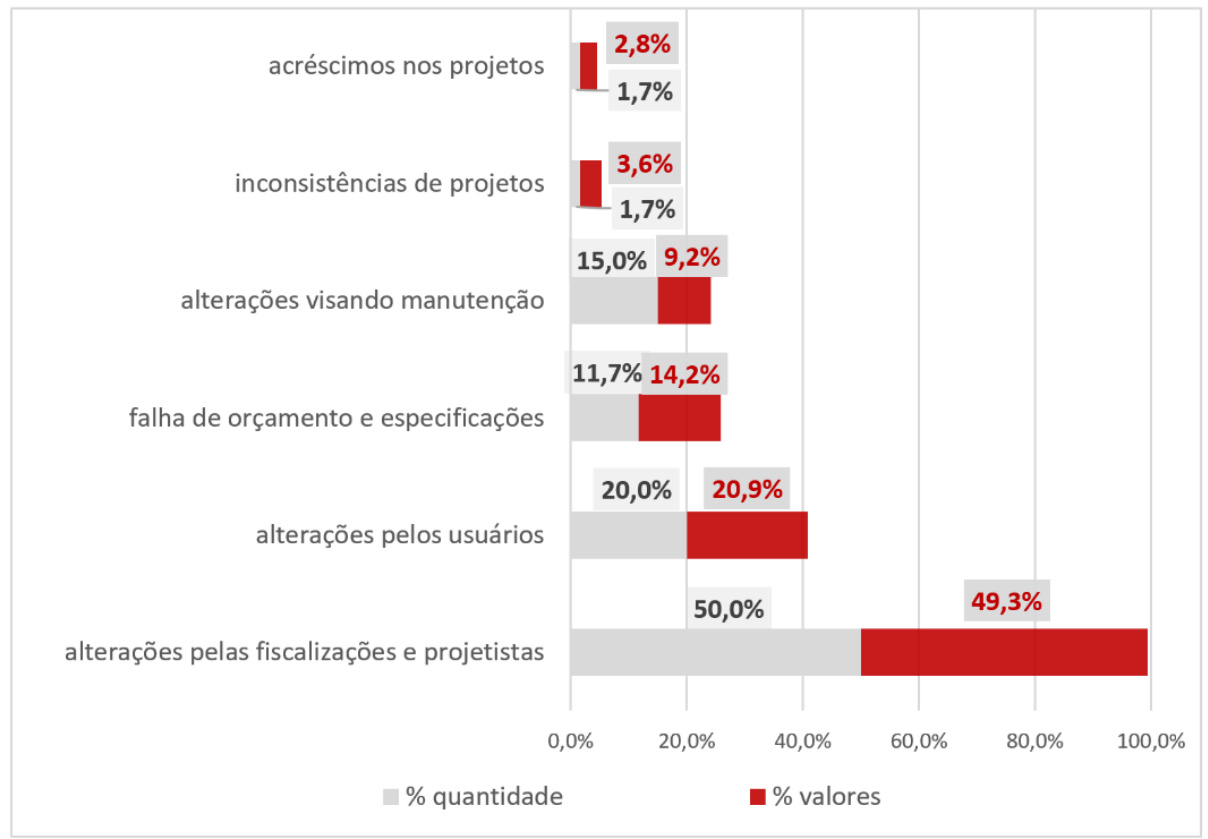


Figura 14 - Composição dos impactos quantitativos e financeiros dos aditivos por causa

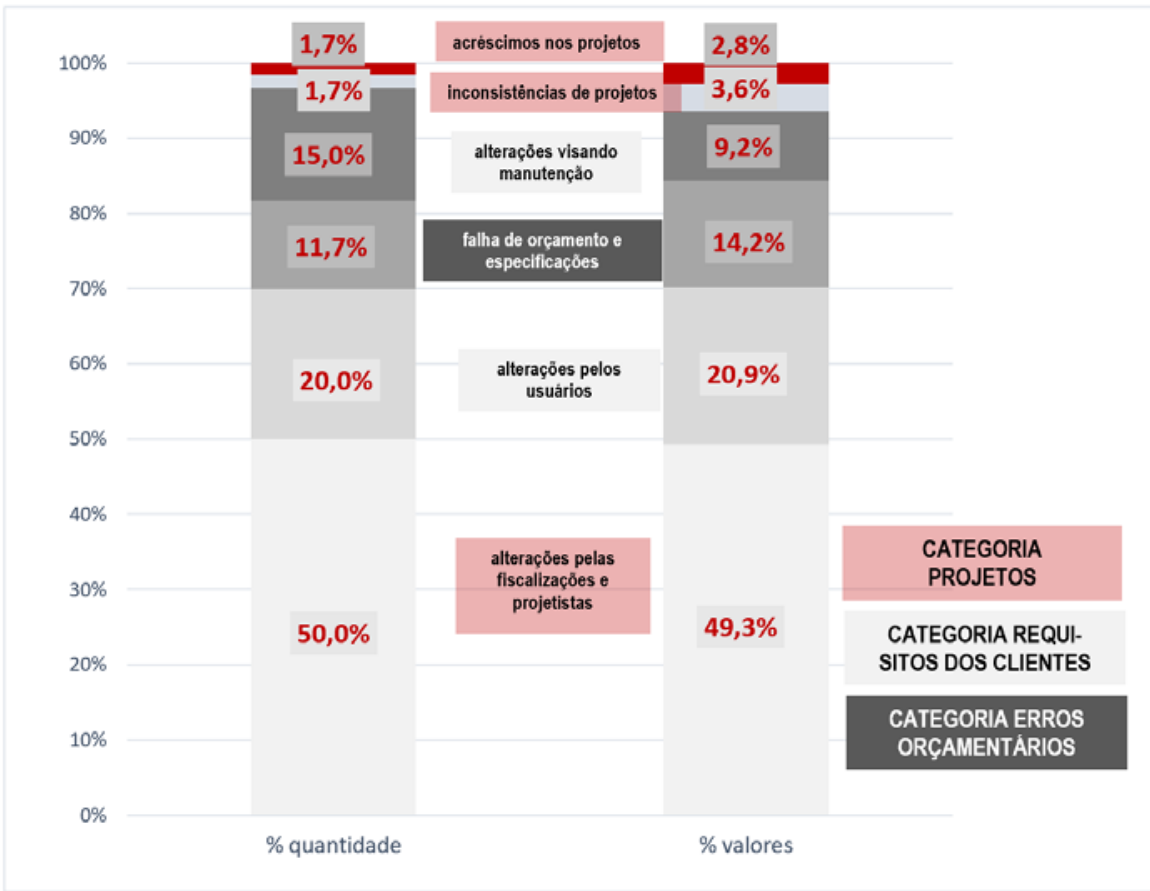

Figura 15 - Análise comparativa de obra e valor do aditivo por categoria de causa

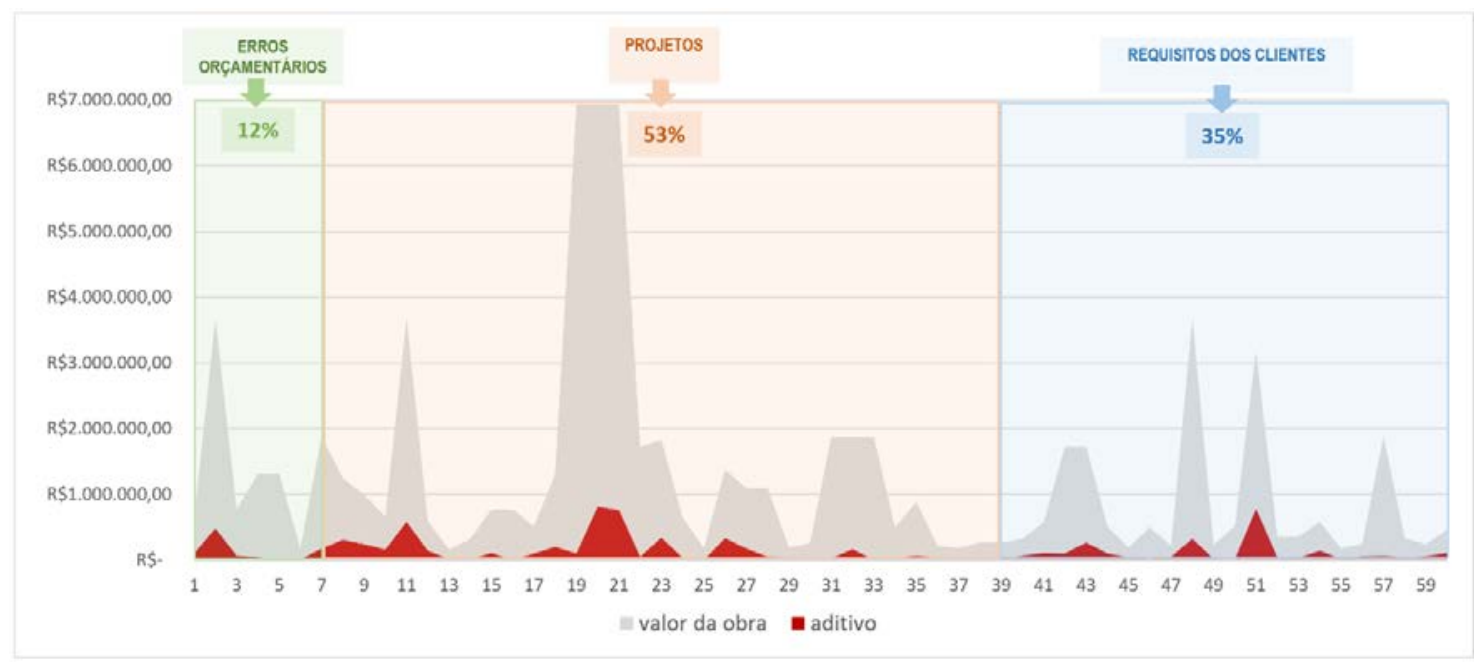

A Tabela 4 resume o impacto financeiro e a frequência por categoria de causa, a partir das análises gráficas das Figuras 14 e 15.

A construção da matriz de risco, ilustrada na Figura 16, possibilita compreender a classificação do risco.

A saída da matriz de risco fornece a classificação do risco com níveis de significância. As causas relacionadas aos projetos corresponderam ao nível mais alto de risco para geração dos custos adicionais.

As causas relacionadas aos clientes também receberam um índice de risco alto, em grande parte devido à expressiva probabilidade (alta) e significativo impacto (alto) atribuídos a essa categoria de causas, que reúne as solicitações provenientes dos usuários e aquelas que requerem melhorias voltadas à manutenção.

As falhas de orçamentos possuem um índice de risco moderado, devido a sua menor frequência e menor impacto financeiro registrados entre as justificativas de aditivos. 
Tabela 4 - Resumo do impacto financeiro e frequência por categoria de causa

\begin{tabular}{|c|c|c|c|c|c|}
\hline \multicolumn{2}{|c|}{ CATEGORIAS DE CAUSAS } & \multicolumn{2}{|c|}{$\begin{array}{l}\text { FREQUENCIA } \\
\text { (IMPACTO } \\
\text { QUANTITATIVO) }\end{array}$} & \multicolumn{2}{|c|}{$\begin{array}{c}\text { IMPACTO } \\
\text { FINANCEIRO }\end{array}$} \\
\hline $\begin{array}{c}\text { ERROS } \\
\text { ORÇAMENTÁRIOS }\end{array}$ & $\begin{array}{c}\text { A1 (falha de orçamento e } \\
\text { especificações) }\end{array}$ & \multicolumn{2}{|c|}{$12 \%$} & \multicolumn{2}{|c|}{$14 \%$} \\
\hline \multirow{3}{*}{ PROJETOS } & A2 (acréscimos de projetos) & $1,7 \%$ & \multirow{3}{*}{$53 \%$} & $3,6 \%$ & \multirow{3}{*}{$56 \%$} \\
\hline & $\begin{array}{l}\text { A3 (incompatibilidades de } \\
\text { projetos) }\end{array}$ & $1,7 \%$ & & $2,8 \%$ & \\
\hline & $\begin{array}{l}\text { B3 (alterações devido a } \\
\text { fiscalização e projetistas) }\end{array}$ & $50 \%$ & & $49,3 \%$ & \\
\hline \multirow{2}{*}{$\begin{array}{l}\text { REQUISITOS DOS } \\
\text { CLIENTES }\end{array}$} & $\begin{array}{l}\text { B1 (alterações visando } \\
\text { manutenção) }\end{array}$ & $15 \%$ & \multirow{2}{*}{$35 \%$} & $9,2 \%$ & \multirow{2}{*}{$30 \%$} \\
\hline & $\begin{array}{l}\text { B2 (alterações devido a } \\
\text { solicitações dos usuários) }\end{array}$ & $20 \%$ & & $20,9 \%$ & \\
\hline
\end{tabular}

Figura 16 - Matriz de risco para as categorias de causas dos aditivos financeiros

\begin{tabular}{|c|c|c|c|c|c|}
\hline \multirow{6}{*}{ 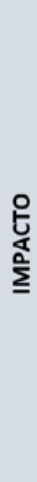 } & \multicolumn{5}{|c|}{ PROBABILIDADE } \\
\hline & $\begin{array}{l}\text { MATRIZ DO } \\
\text { RISCO }\end{array}$ & BAIXA & MODERADA & ALTA & MUITO ALTA \\
\hline & MUITO ALTO & 4 & 8 & 12 & $\begin{array}{l}16 \\
\text { PROJETOS }\end{array}$ \\
\hline & ALTO & 3 & 6 & ${ }^{9}$ CLIENIES & 12 \\
\hline & MODERADO & 2 & ${ }^{4}$ ORÇAMENTOS & 6 & 8 \\
\hline & BAIXO & 1 & 2 & 3 & 4 \\
\hline
\end{tabular}

Cabe ressaltar que as causas relacionadas aos projetos percebidas antes da obra possuem menor probabilidade e impacto entre todas as outras causas. No entanto, as causas relacionadas aos projetos detectadas após a contratação da obra sobrepõem todas as demais, correspondendo ao maior índice de risco.

\section{Conclusões}

A literatura internacional revelou uma expressiva quantidade de trabalhos com foco nos custos adicionais. Grande parte desses estudos também está vinculada aos adicionais de prazos. Contudo, uma menor parte refere-se à prática em obras públicas.

Sob o enfoque do gerenciamento de risco, percebeu-se que significativa parte dos estudos que buscaram compreender as causas dos custos adicionais pautou-se em pesquisas cuja avaliação da importância (impacto) e da probabilidade das causas foi definida por grupos de profissionais envolvidos nas várias etapas relacionadas às obras. A maior parte dos estudos propõe listas de fontes de causas, sem a consideração diferenciada dos termos que envolvem o gerenciamento do risco.

Esta é uma das contribuições da pesquisa: propor uma classificação das categorias para análise do risco relacionado aos custos adicionais em empreendimentos, considerando a taxonomia da área temática que diferencia fontes de vulnerabilidade, fontes de risco, eventos de risco e a consequência do risco que, no caso da presente pesquisa, é o adicional de custo.

O modelo apresentado para categorização das causas dos custos adicionais foi proposto para obras públicas, porém pode servir também de base para análises do risco relacionado ao adicional de custos em outros segmentos de empreendimentos. Isso se deve ao fato de que a taxonomia utilizada fornece uma estrutura confiável e prática que pode ser ajustada para outros tipos de projetos de construção, uma vez que também foi baseada em diferentes estudos de inúmeros países. Todas as fontes de vulnerabilidade e risco listadas nas categorias propostas também podem ser identificadas em obras do setor privado. 
A taxonomia utilizada também é similar quanto à inter-relação dos termos pertinentes à outra tradicional consequência do risco, o adicional de prazo. Ao se adotar um modelo que estabelece uma sistemática dos termos, facilita-se o processo de rastreabilidade da causa-raiz, em especial pela compreensão dos fatores de vulnerabilidade que afetam a probabilidade de ocorrência dos fatores de risco.

Outra contribuição do trabalho diz respeito à análise das causas dos custos adicionais, no caso dos aditivos contratuais, por meio da análise das justificativas documentadas. Ainda que essa análise documental demande o apoio de análises lexicais para garantir o rigor científico, existe o ganho do contexto de confiabilidade para a construção dos índices de risco a partir de dados registrados em detrimento de uma possível variação significativa na atribuição de escalas segundo a percepção de profissionais envolvidos nos processos.

Os cálculos estatísticos que envolveram as análises multivariadas dos dados textuais permitiram associações significativas que garantiram maior precisão para definição das categorias de causas e posterior classificação de cada aditivo analisado em uma das categorias estabelecidas.

Quanto aos resultados, as alterações devido às solicitações da fiscalização ou projetistas constituem a fonte de risco de maior incidência, tanto em número, 30 aditivos, como em valor, representando cerca de $50 \%$ do custo total dos aditivos. Esse resultado corrobora o pressuposto de que as intervenções que resultam em serviços a serem adicionados em contrato de obras públicas devem sempre partir da fiscalização ou dos projetistas, com justificativas técnicas adequadas, conforme dispõe a Lei das Licitações, art. 65 (BRASIL, 1993).

O grande número de solicitações pelos projetistas, fiscais e usuários impactou financeiramente os contratos, em especial nos itens instalações elétricas e superestrutura, que são itens comumente representativos nas planilhas orçamentárias de obras.

O maior índice de risco foi associado à categoria de projetos, corroborando a maior parte das pesquisas nos âmbitos nacional e internacional, revelada na revisão sistemática da literatura. A categoria de causas relacionadas aos requisitos dos clientes também possui um alto índice de risco. A categoria relacionada às falhas de orçamentos obteve um índice moderado quanto ao risco relacionado aos aditivos financeiros.

A importância do projeto básico é notória, devendo ser desenvolvido de forma objetiva e precisa, no intuito de se evitar modificações, adaptações ou reformulações durante a execução do contrato. Apesar dessa necessidade, como levantado pelos dados coletados na pesquisa, nota-se a existência de aditivos contratuais oriundos de falhas nos orçamentos e especificações e, ainda, por inconsistência de projetos, porém essas não são as justificativas mais recorrentes nos processos analisados, e, sim, as alterações devido às solicitações da fiscalização ou dos projetistas.

Esse comportamento muitas vezes justifica-se pelo fato de que a necessidade levantada no início do processo sofre alterações no decorrer do tempo, que engloba etapas muitas vezes morosas dos procedimentos licitatórios.

É possível que alterações solicitadas pelos usuários ou visando à manutenção poderiam ter sido prevenidas na fase de projeto, podendo estar associadas a outros fatores de vulnerabilidade que, ainda que relacionados aos clientes, fazem parte do processo projetual. Essa análise demandaria outra investigação de rastreabilidade, porém a classificação proposta com base na taxonomia dos termos do risco permite compreender com mais clareza essas inter-relações.

Depreende-se dessa análise que a celebração de aditivos deve ser objeto de fiscalização rigorosa por parte dos agentes envolvidos em contratos de construção de obras públicas, tanto na fase interna e externa da licitação, quanto durante a execução dessas obras para evitar custos adicionais que geram dano ao erário.

Os dados apresentados podem subsidiar os setores responsáveis pelo planejamento da instituição, em casos de projeção ou distribuição de recursos destinados à ampliação do espaço físico. A análise de quais itens dos orçamentos das obras tiveram maior ocorrência de acréscimos contratuais pode ajudar os gestores na identificação de falhas no projeto básico das obras e prever necessidades que surjam durante a construção da obra, mitigando seu risco.

\section{Referências}

AHIAGA-DAGBUI, D. D.; SMITH, S. D. My cost runneth over: data mining to reduce construction cost overruns. In: ANNUAL CONFERENCE OF THE ASSOCIATION OF RESEARCHERS IN CONSTRUCTION MANAGEMENT, 29., United Kingdom, 2013. Proceedings [...] United Kingdom, 2013. 
AHSAN, K.; GUNAWAN, I. Analysis of cost and schedule performance of international development projects. International Journal of Project Management, v. 28, n. 1, p. 68-78, 2010.

ALINAITWE, H.; APOLOT, R.; TINDIWENSI, D. investigation into the causes of delays and cost overruns in Uganda's public sector construction projects. Journal of Construction in Developing Countries, v. 18, n. 2, p. 33, 2013.

AMUSAN, L. M. et al. Data exploration on factors that influences construction cost and time performance on construction project sites. Data in Brief, v. 17, p. 1320-1325, 2018.

ARDITI, D.; AKAN, G. T.; GURDAMAR, S. Cost overruns in public projects. International Journal of Project Management, v. 3, n. 4, p. 218-224, 1985.

ASSOCIAÇÃO BRASILEIRA DE NORMAS TÉCNICAS. NBR ISO 31000: gestão de risco: princípios e diretrizes. Rio de Janeiro, 2018.

ASSOCIAÇÃO BRASILEIRA DE NORMAS TÉCNICAS. NBR ISO/IEC 31010: gestão de risco: técnicas para o processo de avaliação de riscos. Rio de Janeiro, 2012.

ASSOCIAÇÃO BRASILEIRA DE NORMAS TÉCNICAS. NBR ISO/TR 31004: gestão de risco: guia para implementação da ABNT NBR ISO 31000. Rio de Janeiro, 2015.

BALOYI, L.; BEKKER, M. Causes of construction cost and time overruns: the 2010 FIFA World Cup stadia in South Africa. Acta Structilia, v. 18, n. 1, p. 51-67, 2011.

BELTRÃO, L. M. P.; CARVALHO, M. T. M. Prioritizing construction risks using fuzzy AHP in Brazilian public enterprises. Journal of Construction Engineering and Management, v. 145, n. 2, p. 05018018, 2019.

BRASIL. Lei no 8666, de 21 de junho de 1993, que institui normas para licitações e contratos da Administração Pública e dá outras providências. Disponível em:

<http://www.planalto.gov.br/ccivil_03/leis/18666cons.htm>. Acesso em: 10 mar. 2019.

CANO, A.; CRUZ, M. P. Integrated methodology for project risk management. Journal of Construction Engineering and Management, v. 128, n. 6, p. 473-485, 2002.

CHAN, D. W. et al. Risk ranking and analysis in target cost contracts: empirical evidence from the construction industry. International Journal of Project Management, v. 29, n. 6, p. 751-763, 2011.

CHENG, Y. An exploration into cost-influencing factors on construction projects. International Journal of Project Management, v. 32, n. 5, p. 850-860, 2014.

CREEDY, G. D. Risk factors leading to cost overrun in the delivery of highway construction projects. 2006. $260 \mathrm{f}$. Thesis (Doctor of Philosophy) - Queensland University of Technology, School of Urban Development, 2006.

DADA, J. O.; JAGBORO, G. O. An evaluation of the impact of risk on project cost overrun in the Nigerian construction industry. Journal of Financial Management of Property and Construction, v. 12, n. 1, p. 37-44, 2007.

DIKMEN, I.; BIRGONUL, M. T.; FIDAN, G. Assessment of project vulnerability as a part of risk management in construction. in: JOINT CIB W065/W055 SYMPOSIUM, Dubai, 2008. Proceedings [...] Dubai, 2008.

DOLOI, H. et al. Analysing factors affecting delays in indian construction projects. International Journal of Project Management, v. 30, n. 4, p. 479-489, 2012.

DOLOI, H. K. Understanding stakeholders' perspective of cost estimation in project management.

International Journal of Project Management, v. 29, n. 5, p. 622-636, 2011.

DRESCH, A.; LACERDA, D. P.; ANTUNES JÚNIOR, J. A. V. Design science research: método de pesquisa para avanço da ciência e tecnologia. Porto Alegre: Bookman, 2015.

ENSHASSI, A.; AL-NAJJAR, J.; KUMARASWAMY, M. Delays and cost overruns in the construction projects in the Gaza strip. Journal of Financial Management of Property and Construction, v. 14, n. 2, p. 126-151, 2009.

FAMIYEH, S. et al. Major causes of construction time and cost overruns: a case of selected educational sector projects in Ghana. Journal of Engineering, Design and Technology, v. 15, n. 2, p. 181-198, 2017. 
FIDAN, G. et al. Ontology for relating risk and vulnerability to cost overrun in international projects. Journal of Computing in Civil Engineering, v. 25, n. 4, p. 302-315, 2011.

FLANAGAN, R.; NORMAN, G. Risk management and construction. Oxford: Blackwell Publishing, 1993.

FUNDAÇÃO GETÚLIO VARGAS. FGV dados. Portal IBRE, 2019.

GIL, A. C. Métodos e técnicas de pesquisa social. São Paulo: Atlas, 2008.

GUNDUZ, M.; MAKI, O. L. Assessing the risk perception of cost overrun through importance rating. Technological and Economic Development of Economy, v. 24, n. 5, p. 1829-1844, 2018.

HSIEH, T.; LU, S.; WU, C. Statistical analysis of causes for change orders in metropolitan public works. International Journal of Project Management, v. 22, n. 8, p. 679-686, 2004.

KENG, T. C.; MANSOR, N.; CHING, Y. K. An exploration of cost overrun in building construction projects. Global Business and Management Research, v. 10, n. 3, p. 638, 2018.

KIM, S. Y. et al. Cost overrun factor analysis for hospital projects in Vietnam. KSCE Journal of Civil Engineering, v. 22, n. 1, p. 1-11, 2018.

KITCHENHAM, B. Procedures for performing systematic reviews. Keele University Technical Report TR/SE-0401, Keele, UK, v. 33, 2004.

LAHLOU, S. L'analyse lexicale. Variances, n. 3, p. 13-24, 1994.

LOVE, P. E. D. et al. Using systems dynamics to better understand change and rework in construction project management systems. International Journal of Project Management, v. 20, n. 6, p. 425-436, 2002.

LOVE, P. E. et al. Rework in civil infrastructure projects: determination of cost predictors. Journal of construction Engineering and Management, v. 136, n. 3, p. 275-282, 2010.

MAGNUSSEN, O. M.; OLSSON, N. O. E. Comparative analysis of cost estimates of major public investment projects. International Journal of Project Management, v. 24, n. 4, p. 281-288, 2006.

MAHAMID, I.; DMAIDI, N. Risks leading to cost overrun in building construction from consultants' perspective. Organization, Technology \& Management in Construction: an International journal, v. 5, n. 2, p. 860-873, 2013.

MANSFIELD, N. R.; UGWU, O. O.; DORAN, T. Causes of delay and cost overruns in Nigerian construction projects. International Journal of Project Management, v. 12, n. 4, p. 254-260, 1994.

MCGRAW HILL CONSTRUCTION. Managing uncertainty and expectations in building design and construction. Smart Market Report. 2014.

MENEZES, P. S. N. Entre a engenharia e a administração: fatores determinantes na contratação de serviços adicionais em obras públicas. Belo Horizonte, 2013. 73 f. Dissertação (Mestrado em Administração) - Faculdade de Estudos Administrativos de Minas Gerais, Belo Horizonte, 2013.

MORGAN, D. L. Focus group as qualitative research. London: Sage, 1997.

MUIANGA, E. A. D.; GRANJA, A. D.; RUIZ, J. de A. Desvios de custos e prazos em empreendimentos da construção civil: categorização e fatores de influência. Ambiente Construído, Porto Alegre, v. 15, n. 1, p. 79-97, jan./mar. 2015.

NIAZI, G. A.; PAINTING, N. Significant factors causing cost overruns in the construction industry in Afghanistan. Procedia Engineering, v. 182, p. 510-517, 2017.

OKPALA, D. C.; ANIEKWU, A. N. Causes of high costs of construction in nigeria. Journal of Construction Engineering and Management, v. 114, n. 2, p. 233-244, 1988.

OLADAPO, A. A. A Quantitative assessment of the cost and time impact of variation orders on construction projects. Journal of Engineering, Design and Technology, v. 5, n. 1, p. 35-48, 2007.

PUGH, D. S.; HICKSON, D. J.; HININGS, C. R. An empirical taxonomy of structures of work organizations. Administrative Science Quarterly, v. 14, n. 1, p. 115-126, 1969.

RAMABODU, M. S.; VERSTER, J. J. P. Factors contributing to cost overruns of construction projects. In: BUILT ENVIRONMENT CONFERENCE, 5., 2010. Proceedings [...] Durban South Africa, 2010. 
RAMANATHAN, C.; NARAYANAN, S. P.; IDRUS, A. B. Construction delays causing risks on time and cost-a critical review. Construction Economics and Building, v. 12, n. 1, p. 37-57, 2012.

RATINAUD, P. IRAMUTEQ: Interface de r pour les analyses multidimensionnelles de textes et de questionnaires [COMPUTER software]. 2009. Disponível em: http://www.iramuteq.org. Acesso em: 2 fev. 2019.

REINERT, M. ALCESTE: une méthodologie d'analyse des données textuelles et une application: Aurelia de Gerard de Nerval. Bulletin de méthodologie sociologique, v. 26, n. 1, p. 24-54, 1990.

ROSENFELD, Y. Root-cause analysis of construction-cost overruns. Journal of Construction Engineering and Management, v. 140, n. 1, 2014.

SALVIATI, M. E. Manual do aplicativo Iramuteq. Planaltina, 2017. 93 p. Disponível em: http://www.iramuteq.org/documentation/fichiers/manual-do-aplicativo-iramuteq-par-maria-elisabethsalviati. Acesso em: 2 fev. 2019.

SAMBASIVAN, M.; SOON, Y. W. Causes and effects of delays in malaysian construction industry. International Journal of Project Management, v. 25, n. 5, p. 517-526, 2007.

SANTOS, H. P.; STARLING, C. M. D.; ANDERY, P. R. P. um estudo sobre as causas de aumentos de custos e de prazos em obras de edificações públicas municipais. Ambiente Construído, Porto Alegre, v. 15, n. 4, p. 225-242, out./dez. 2015.

SHEHU, Z.; ENDUT, I. R.; AKINTOYE, A. Factors contributing to project time and hence cost overrun in the malaysian construction industry. Journal of Financial Management of Property and Construction, v. 19, n. 1, p. 55-75, 2014.

SHELBOURN, M. A. et al. A framework for effective collaborative working in construction. Proceedings of the Institution of Civil Engineers, 2007.

TAH, J. H. M.; CARR, V. Information modeling for construction project risk management system. Engineering, Construction and Architectural Management, v. 7, n. 2, p. 107-119, 2000.

TRIVIÑOS, A. N. S. Pesquisa qualitativa: introdução à pesquisa em ciências sociais: a pesquisa qualitativa em educação. São Paulo: Atlas, 1987.

WANJARI, S. P.; DOBARIYA, G. Identifying factors causing cost overrun of the construction projects in India. Sādhanā, v. 41, n. 6, p. 679-693, 2016.

YIN, R. K. Estudo de caso: planejamento e métodos. Porto Alegre: Bookman, 2015.

\section{Maria Carolina Gomes de Oliveira Brandstetter}

Escola de Engenharia Civil e Ambiental | Universidade Federal de Goiás | Avenida Universitãria, Quadra 86, Área 1488, Leste Universitário | Goiânia - GO - Brasil | CEP 74605-220 | Tel.: (62) 3209-6086 | E-mail: mariacarolina.brands@gmail.com

\section{Helen Regina de Oliveira e Ribeiro}

Escola de Engenharia Civil e Ambiental | Universidade Federal de Goiás | E-mail: helenreginaeng@hotmail.com

\section{Ambiente Construído}

Revista da Associação Nacional de Tecnologia do Ambiente Construído

Av. Osvaldo Aranha, 99 - 3o andar, Centro

Porto Alegre - RS - Brasil

CEP $90035-190$

Telefone: +55 (51) 3308-4084

Fax: +55 (51) 3308-4054

www. seer. ufrgs. br/ ambienteconstruido

E-mail: ambienteconstruido@ufrgs.br 